\title{
Estado da arte da democracia digital no Brasil: oferta e sobrevivência das iniciativas (1999-2016)
}

Rafael Cardoso Sampaio

Universidade Federal do Paraná (UFPR)

Sérgio Braga

Universidade Federal do Paraná (UFPR)

Marcio Cunha Carlomagno

Universidade Federal do Paraná (UFPR)

Djiovanni Jonas França Marioto

Universidade Federal do Paraná (UFPR)

Murilo Brum Alison

Universidade Federal do Paraná (UFPR)

Tiago Philippini Ferreira Borges da Silva

Universidade Federal do Paraná (UFPR)

Esta pesquisa busca fazer uma apresentação compreensiva sobre o atual estado da arte da oferta de iniciativas de democracia digital pelo Estado brasileiro. Com base em uma série de prospecções e levantamentos, montamos um banco de dados com 125 iniciativas de 1999 a 2016, que foram classificadas por análise de conteúdo por ano de lançamento e encerramento, poder, esfera governamental, temporalidade, se a ferramenta estava ativa ou não, fase do ciclo de políticas públicas, plataforma digital e valor democrático. Realizamos, inicialmente, testes de correspondências múltiplas para entender quais os valores democráticos mais ligados a cada poder ou nível no Brasil. Posteriormente, fizemos testes de sobrevivência para compreender fatores que podem levar as iniciativas a serem encerradas prematuramente. Os resultados indicam que o Executivo federal é o que lança mais iniciativas, que são, em sua maioria, realizadas na fase de implementação de políticas públicas, sendo mais ligadas ao monitoramento de obras, contas ou políticas, permanentes e baseadas em websites. Elas tendem a ser lançadas em anos ímpares e são propensas a ser abandonadas entre um e três anos.

Palavras-chave: democracia digital, governança digital, serviços digitais

[Artigo recebido em 12 de novembro de 2018. Aprovado em 18 de setembro de 2019.] 
Estado del arte de la democracia digital en Brasil: oferta y supervivencia de iniciativas (1999-2016)

Resumen: Esta investigación busca hacer una presentación comprensiva sobre el actual estado del arte de la oferta de iniciativas de democracia electrónica por el estado brasileño. Con base en una serie de prospecciones y levantamientos, montamos un banco de datos con 125 iniciativas de 1999 a 2016, que fueron clasificadas por análisis de contenido por año de lanzamiento y cierre, poder, esfera gubernamental, temporalidad, si la herramienta estaba activa o no, fase del ciclo de políticas públicas, plataforma digital y valor democrático. Realizamos, inicialmente, pruebas de correspondencia múltiple para entender qué valores democráticos estaban más relacionados a cada poder o nivel en Brasil. Posteriormente, hicimos pruebas de supervivencia para comprender factores que pueden llevar a las iniciativas a cerrarse prematuramente. Los resultados indican que el Poder Ejecutivo federal es el que lanza más iniciativas, que son, en su mayoría, realizadas en la fase de implementación de políticas públicas, siendo más relacionadas al monitoreo de obras, cuentas o políticas, permanentes y basadas en web sitios. Ellas tienden a ser lanzadas en años impares y son propensas a ser abandonadas entre uno y tres años.

Palabras-clave: democracia electrónica, gobernación digital, servicios digitales

\section{State of the art of e-democracy in Brazil: offer and survival of initiatives (1999-2016)}

This research seeks to produce a comprehensive presentation on the current offer of e-democracy initiatives by the Brazilian State. Based on a series of reports and mappings, we set up a database of 125 initiatives from 1999 to 2016, which were classified by content analysis by year of launch and closure, branches of power, government sphere, temporality, whether the tool was active or no, phase of public policy cycle, digital platform and democratic value. We initially carried out multiple correspondences analysis to understand the democratic values most related to each power or level in Brazil. Subsequently, we performed survival tests to understand factors that may lead to initiatives being terminated prematurely. The results indicate that the Federal Executive branc is the one that launches more initiatives, which are mostly carried out in the implementation phase of public policies, being more linked to the monitoring of works, accounts or politics, permanent and based on websites. They tend to be released in odd years and are prone to being abandoned between one and three years.

Keywords: e-democracy, digital governance, digital services 


\section{Introdução}

No atual patamar de alcance das tecnologias de comunicação e informação, notadamente a internet, a presença do Estado, no geral, e dos governos, em específico, em ambientes digitais passou a ser mandatória. Se, inicialmente, a demanda partiu de setores do próprio Estado que passaram a utilizar microcomputadores e tecnologias similares para digitalizar documentos e funções do estado, atualmente, os governos precisam ter facetas digitais (geralmente na forma de websites e aplicativos), entregar e oferecer serviços digitais de diferentes naturezas e mesmo interagir com cidadãos em diferentes plataformas digitais, especialmente as redes sociais online.

Para além da simples interação, há um corpo bastante robusto de literatura que tenta compreender como o emprego de tais tecnologias digitais e online de comunicação podem ser utilizados de forma suplementar, reforçar ou corrigir aspectos das práticas políticas e democráticas (COLEMAN; BLUMLER, 2009; DAHLBERG, 2011; Gomes, 2011, 2016; MendonÇA; Pereira; FilgueIras, 2016; VAN DiJK, 2012; VEDEL, 2006). Em outras palavras, se tais ferramentas não podem ser meios ou instrumentos de democracia digital, tendo como foco um aumento do poder da capacidade concorrencial do cidadão frente a outros atores políticos (GOMES, 2011).

Como já discutido por Coleman e Blumler (2009), e Gomes (2016), desde antes da existência da internet que há discussões e estudos sobre os usos de tecnologias para incrementar a democracia, porém é algo que ganha corpo com o surgimento da internet, da world wide web, e do uso massivo de microcomputadores pessoais. Ora, se de um lado existe uma avaliação de crise da representação política, de afastamento entre governantes e governados, de apatia e cinismo político por parte dos cidadãos cada vez menos interessados na política, o que, por sua vez, tende a levar a polarizações e extremismo; de outro lado, supostamente, as "novas" tecnologias digitais online pareciam ofertar canais para uma interação mais direta entre representantes e representados evitando, em grande medida, os filtros de partidos políticos e da mídia profissional.

Evitando a querela do que a internet pode fazer pela democracia, o campo da democracia digital tem se dedicado a estudar sistematicamente todo tipo de iniciativa, projeto ou ferramenta que possa, de fato, gerar impactos democráticos positivos, tentando inclusive compreender os fatores técnicos e políticos que podem ser mais determinantes para seu sucesso ou não (CHADWICK, 2011; GOMES, 2011; MACINTOSH; WHYTE, 2008). Não obstante, especificamente no caso brasileiro, detectamos que tais estudos apresentam duas limitações fundamentais. De forma geral, ou são muito normativos, apenas tentando compreender ganhos e perdas 
em termos de valores democráticos, ou são muito restritos a estudos de caso. Em ambos os casos, acreditamos que não existam discussões amplas sobre a criação e manutenção das inciativas de democracia digital.

Buscando suprir tal lacuna, montamos um banco com dados secundários agregados de diferentes relatórios e pesquisas, que se preocuparam anteriormente com a prospecção de tais iniciativas de democracia digital. Em outras palavras, a pesquisa oferece um retrato de todas as iniciativas já elencadas em grandes prospecções realizadas por diferentes pesquisadores e centros de pesquisa, oferecendo então uma "fotografia" do momento atual (até 2016). Tal fotografia, ou, simplesmente, estado da arte, justifica-se pelas dificuldades de manutenção de tais objetos. Primeiramente, muitos podem ser apenas "pilotos" (experiências, testes etc.) que frequentemente não sobrevivem aos primeiros anos, seja por algum tipo de resistência institucional ou política, seja por não terem sido considerados bemsucedidos (e aqui entram diferentes visões do que seria o sucesso). Em segundo lugar, tais como diversas outras políticas públicas, tais objetos são, geralmente, afetados diretamente por mudanças políticas (e.g. mudança do partido da prefeitura), sendo encerrados ou modificados radicalmente (incluindo o nome e objetivos primários).

Diante disso, testamos três hipóteses principais, nomeadamente:

Hipótese 1: iniciativas ou ferramentas de nível federal (esfera de governo) tendem a ter tempo de sobrevivência maior do que suas correspondentes dos planos estadual e municipal.

Isso ocorre em função da distribuição de arrecadação fiscal brasileira, em que o Poder Executivo federal detém a maior parte da arrecadação e, portanto, tende a ter maiores recursos para manter tais iniciativas.

Hipótese 2: iniciativas ou ferramentas do Poder Judiciário tendem a ter tempo de sobrevivência maior do que suas correspondentes dos Poderes Executivo e Legislativo.

Por apresentar um corpo de integrantes estável, que pode adotar políticas públicas mais perenes, de longo prazo, o Judiciário seria menos suscetível a mudanças do contexto político do que o Legislativo e o Executivo.

Hipótese 3: iniciativas ou ferramentas permanentes tendem a ter tempo de sobrevivência maior do que suas correspondentes do tipo ocasional ou sazonal, visto que estes dois últimos tipos, por serem intermitentes, ofertam uma constante possibilidade de reavaliação da iniciativa/ferramenta, também diminuindo os custos políticos de finalização da ferramenta, frente aos custos daquela primeira.

Assim, a primeira seção faz uma discussão teórica acerca do conceito de democracia digital, enfatizando-se a sua materialização através de iniciativas em projetos. Em seguida, explicamos a metodologia de preenchimento dos 
dados baseada em buscas na web e em análise de conteúdo quantitativa, e os testes realizados. A terceira seção apresenta os resultados pelo uso de estatística descritiva, por testes de sobrevivência das iniciativas e por testes de correspondências múltiplos.

\section{Estado da arte da democracia digital}

Para facilitar nossa discussão, iniciamos pelo conceito motriz, que será vital para nosso estudo, nomeadamente a democracia digital. Pode-se compreendêla, genericamente, enquanto o uso de tecnologias de comunicação e informação para o avanço de valores democráticos ou, simplesmente, para facilitar atividades democráticas (Coleman; Blumler, 2009; Dahlberg, 2011; MendonçA; Pereira; FilgueIRAS, 2016; VAN DIJK, 2012; Vedel, 2006). Conforme Wilson Gomes, a democracia digital é:

qualquer forma de emprego de dispositivos (computadores, celulares, smart phones, palmtops, ipads...), aplicativos (programas) e ferramentas (fóruns, sites, redes sociais, medias sociais...) de tecnologias digitais de comunicação para suplementar, reforçar ou corrigir aspectos das práticas políticas e sociais do Estado e dos cidadãos em benefício do teor democrático da comunidade política (GOMES, 2011, p.27-28).

Nesse sentido, Gomes aposta em uma visão mais ampla, que valoriza diferentes valores políticos que sejam importantes aos Estados democráticos, dentre os quais: liberdade de expressão, opinião e participação, accountability, transparência, incremento de pluralismo, da representação das minorias e uma consolidação de direitos de grupos ou indivíduos mais vulneráveis na sociedade (GOMES, 2011, p. 28). Ou seja, mais que enfatizar este ou aquele bem democrático ou modelo de democracia, busca-se compreender a complexidade das democracias e a necessidade de iniciativas e meios que fortaleçam de maneira ampla a cidadania e, em consequência, a soberania popular. Assim, para serem democraticamente relevantes, Gomes defende que as iniciativas de e-democracia devem promover, ao menos, um dos três princípios abaixo: 1 - fortalecimento da capacidade concorrencial da cidadania (aumentar e/ou consolidar quotas relevantes do poder do cidadão em relação a outras instâncias na disputa da produção de decisão política, sendo, geralmente, promovido através da transparência ou participação política); 2 - consolidar e reforçar uma sociedade de direitos (assegurar que minorias políticas e setores vulneráveis da sociedade tenham acesso à justiça); 3 - promover o aumento da diversidade de agentes e agendas na discussão pública e nas instâncias de decisão política, aumentando instrumentos, meios e 
oportunidades para que essas minorias se representem ou sejam representadas nas decisões políticas (GoMES, 2011, p. 29-30).

Não obstante tal definição ampliada, os estudos sobre democracia digital não podem se perder no aspecto exclusivamente normativo. Afinal, da mesma maneira que o conceito ou mesmo "a ideia de democracia tem que se confrontar [...] com problemas relacionados ao design institucional que dá forma ao Estado, também a noção de e-democracia precisa ser confrontada com questões relativas aos projetos que a materializam" (GoMES, 2011, p. 2). Logo, "iniciativas [de democracia digital] são projetos ou ideias que articulam ferramentas, dispositivos e aplicativos pararealizar determinadas funções dedicadas a resolver problemas ou alcançar propósitos específicos" (p. 28).

Nessa lógica, uma iniciativa de democracia digital pode tanto se materializar em ferramentas palpáveis, como aplicativos, websites, blogs, fóruns, wikis e afins desenvolvidos especificamente para os objetivos do promotor da democracia digital quanto podem, de fato, ser projetos, iniciativas que buscam avançar os valores democráticos através de instrumentos digitais já existentes, como o uso de sites de redes sociais online para participação política, por exemplo. Note-se que, propositadamente, estamos olhando para uma parte específica da democracia digital, deixando assim, de fora, o que Gomes (2016) trata como "sociedade online", o que inclui movimentos sociais online e formas de protesto e ações coletivas digitais (i.e. ciberativismo), a exemplo das manifestações de junho de 2015. Portanto, nosso foco está, especialmente, em iniciativas top-down de e-democracia (ColEMAN; BLUMLER, 2009), que tendem a ser criadas ou fomentadas por atores estatais.

A literatura brasileira sobre e-democracia pode, a grosso modo, ser dividida em três grandes aspectos: e-participação, deliberação online e transparência digital. A literatura sobre e-participação se focou especialmente na análise aprofundada de diversas iniciativas específicas de e-democracia, estando geralmente restrita a estudos de caso isolados ou mesmo comparações entre poucos objetos. Inspirados nos trabalhos especializados da e-participação com maior ênfase em gestão pública (e.g. CHADWICK, 2011; GRÖNLUND, 2003; MACINTOSH; WHYTE, 2008), tratam-se de análises mais heurísticas e qualitativas, que buscaram compreender diferentes aspectos do desenho institucional das iniciativas, assim como o design das ferramentas digitais empregadas pelas mesmas. Aqui, o objetivo principal é verificar o sucesso da e-participação (quantidade de participantes, qualidade da participação e influência da participação), tanto em termos substantivos quanto em termos mais técnicos (e.g. MAgAlHÃES, 2015; MARQUES, 2010; Araújo; Penteado; Santos, 2015). 
Como definido por Mendonça, Sampaio e Barros (2016), a literatura de deliberação online brasileira se preocupou com dois aspectos principais: redes sociais de conversação e iniciativas de democracia digital. No que tange o segundo aspecto, aquele que nos interessa aqui, os pesquisadores tiveram especial interesse em entender iniciativas de e-participação que apresentassem ferramentas que permitissem o diálogo entre os participantes, notadamente formas de consultas públicas online. Apesar das características das plataformas digitais como um todo (i.e. affordances) e aspectos da criação e gerenciamento dos fóruns serem geralmente considerados, esses estudos destacam-se pela utilização de critérios da teoria da democracia deliberativa (e.g. esfera pública e deliberação pública) para avaliação dos comentários e das conversações digitais (MAIA; REZENDE, 2016; MARtino; MARques, 2012; SARMEnto; MendonçA, 2018), especialmente quando esses subsidiarão a proposição ou alteração de políticas públicas ou mesmo de projetos de lei. Dentre estes, podemos destacar as inúmeras análises sobre os diferentes orçamentos participativos digitais presentes no Brasil (BARROS; SAMPAIO, 2017; Abreu; PINho, 2014; FerreirA, 2012), sobre as diferentes consultas online promovidas durante o Marco Civil da Internet (BARROS, 2016; BRAGATTO; Nicolás; SAMPAIO; 2015; CAPONE; ITUASSU; PeCORARO, 2015) e pelo portal e-Democracia da Câmara dos Deputados (Mıtozo et al., 2016; FARIA et al., 2016; FreitAS et al., 2015).

Por sua vez, a pesquisa sobre e-transparência se voltou mais para a análise de websites governamentais e/ou portais específicos da transparência. Via de regra, os pesquisadores elaboram complexos checklists para verificação de tais plataformas, nos quais avaliam a quantidade e qualidade da informação oferecida, incluindo aí a disposição e facilidade de busca de diferentes informações, assim como a apresentação de relatórios fiscais, técnicos e políticos que incrementem a transparência das diferentes instâncias políticas. Tais pesquisas tendem a verificar, comparativamente, inúmeros websites e elaborar rankings entre os órgãos verificados (PINHO, 2008; RAUPP; PERFOLL, 2017). Geralmente, os checklists formam índices ou valores que permitem uma análise estatística sofisticada (e.g. ALMADA; AMORIM, 2016). Recentemente, a literatura sobre governo aberto e, especialmente, dados abertos, também ganhou força. Para além dos checklists mencionados anteriormente, aqui também há uma preocupação em se verificar os sites a tornarem disponíveis dados abertos e qual a qualidade efetiva desses bancos de dados (Possamal, 2016, Silva et al., 2018).

Todavia, há uma carência sobre estudos mais abrangentes que verifiquem o efetivo estado da arte da oferta de iniciativas de democracia digital, não se restringindo a um valor democrático específico. A grande exceção é o abrangente e representativo estudo realizado pelo Centro Regional para o Desenvolvimento da 
Sociedade da Informação (Cetic) (CGI, 2018; RIBEIRO; BARBOSA, 2016), realizado em todas as instâncias de governo no Brasil, que busca verificar o estado da arte do governo eletrônico no Brasil, incluindo variáveis sobre a oferta de e-participação e sobre e-transparência. O estudo, entretanto, é feito através de survey com representantes dos diferentes órgãos públicos brasileiros e não busca mapear o efetivo estado da arte da oferta das iniciativas em si.

Buscando sanar essa lacuna na literatura, foram reunidas todas as prospecções sobre democracia digital encontradas a respeito de iniciativas brasileiras (BARROS, 2017; FundaÇÃo GetúlIo VARgas, 2015a, 2015b; CENTRO DE Estudos AVANÇAdos em Democracia Digital 2010, 2011, 2015; Possamai, 2016; SAMPaio, 2014) que foram utilizadas como os dados primários para nosso próprio estudo. O objetivo era justamente não desperdiçar esforços anteriores e criar um banco de dados mais abrangente possível sobre o estado da arte das iniciativas de democracia digital já ofertadas.

Em especial, outro fator motivador para a reunião das diferentes prospecções era a verificação da vida de tais projetos. Há indicativos de que a oferta de iniciativas de democracia digital tende a ser influenciada pelo contexto político dos ofertantes. Apesar de estudos demonstrarem que não há uma ligação com a ideologia partidária para a oferta ou qualidade em si (NORRIS, 2001; NICOLÁs; BRAGA, 2015), há fortes indicativos de que mudanças políticas na gestão tendem a encerrar ou modificar consideravelmente os rumos dos projetos (o que inevitavelmente resulta em extinção da iniciativa) (cf. evidenciado por Sampaio, 2014). Como há pouca preocupação com a memória de tais instrumentos de democracia digital e mesmo de comunicação pública no sentido mais amplo (LUZ; WEBER, 2018), o uso de diferentes relatórios também nos soa como a estratégia mais adequada. Assim, além da apresentação do estado da arte da oferta de iniciativas de democracia digital, também realizamos testes de sobrevivência que tentassem nos indicar o que pode ter impacto no encerramento prematuro de um projeto, conforme apresentamos abaixo.

\section{Metodologia}

Essa pesquisa se iniciou como um projeto de iniciação científica, que buscava identificar as principais prospecções a respeito da democracia digital. Encontramos, inicialmente, dois sites que buscaram se tornar repositórios das iniciativas e que pudessem receber uma atualização constante pelos próprios gestores públicos, organizações civis e cidadãos interessados ${ }^{1}$. Percebeu-se, entretanto, que apesar

\footnotetext{
${ }^{1}$ http://democraciadigital.redelivre.org.br e http://democraciadigital.fgv.br. Acesso em 12 mar. 2018.
} 
de seguirem lógicas de busca similares, os relatórios tendiam a apresentar dados díspares. Trata-se, claro, de algo comum em pesquisas de mapeamento e prospecção, porém também ficou claro que a criação de um banco secundário com os resultados dos diferentes estudos tenderia a ser mais abrangente e certamente mais próxima ao verdadeiro estado da arte da oferta de mecanismos, ferramentas, iniciativas, projetos e plataformas de democracia digital em suas mais variadas formas.

Com essa intenção, foram reunidas três prospecções realizadas pelo Centro de Estudos Avançados em Democracia Digital² (CEADD, 2010, 2011, 2015), pelo grupo de pesquisa "Comunicação, Internet e Democracia" da Universidade Federal da Bahia, e uma pesquisa realizada pela Fundação Getúlio Vargas de São Paulo, sob o "Projeto Democracia Digital" (FGV, 2015a; FGV, 2015b). Porém, para não se basear exclusivamente nas duas pesquisas, foram levantados artigos, monografias, dissertações e teses que pudessem ter levantamentos similares, pelo uso das expressões "Democracia digital" OR, "Governo eletrônico" OR, "Governo aberto" + "prospecção" OR, "levantamento" OR, "mapeamento" no google acadêmico, no banco de teses e dissertações da Capes no portal de periódico Capes e na Scielo, e foram encontradas apenas três teses: uma com o estado da arte de orçamentos participativos digitais (SAMPAIO, 2014), uma segunda com o estado da arte de consultas públicas digitais no Brasil (BARRos, 2017), e outra com o estado da arte de portais e iniciativas de dados abertos no país (POSSAMAl, 2016). Assim, o levantamento das três pesquisas foi incorporado em nosso corpus, que está disponível no anexo 2.

Dessas diferentes pesquisas, conseguimos extrair as informações mais básicas sobre cada projeto, tais como nome, URL (link), além da descrição geral, que serviu de guia para o preenchimento de outras informações. Posteriormente, cada codificador ficou a cargo de preencher as seguintes variáveis através da utilização da técnica de análise de conteúdo quantitativa (NEUENDORF, 2002). As variáveis categóricas foram: ano de lançamento, ano de encerramento, Poderes (Executivo, Legislativo, Judiciário), esfera governamental (municipal, estadual, federal), temporalidade (permanente, sazonal ou ocasional), se a ferramenta estava ativa ou não, e fase do ciclo de políticas públicas (agenda, formulação, decisão, implementação e avaliação).

Sob a perspectiva da democracia digital, também adotamos as categorias apresentadas nos relatórios do Instituto Nacional de Ciência e Tecnologia em Democracia Digital (INCT), que buscam identificar o valor democrático mais avançado pela ferramenta ou iniciativa, conforme a descrição abaixo:

\footnotetext{
${ }^{2}$ Atualmente, o CEADD faz parte do Instituto Nacional de Ciência e Tecnologia em Democracia Digital (INCT.DD).
} 
1. Monitoramento de contas, obras e políticas (refere-se à capacidade dos indivíduos e grupos fora da organização para monitorar as atividades e decisões tomadas dentro da organização)

2. Dados abertos (disponibilidade de informações em formato aberto sobre uma organização ou ator)

3. Acompanhamento dos representantes (permite o acompanhamento, por parte da sociedade, de representantes através da disponibilização de informações e ferramentas que facilitam a comunicação, além de mecanismos de prestação de contas)

4. Informação e educação para a cidadania (utilização das TICs como recurso de ativação da cidadania)

5. Expressão de reivindicação civil (ferramentas voltadas para fazer reclamações, denúncias ou pedidos ao órgão público, como 156, Colab)

6. Participação (participação direta da sociedade civil no processo de tomada de decisão, geralmente envolvendo o voto.)

7. Deliberação (formas de participação que envolvam algum tipo de ferramenta dialógica)

8. Direitos e acesso à justiça (ferramentas ou iniciativas que sejam voltadas para minorias e/ou para fortalecimento de direitos individuais e direitos humanos)

\section{Outros}

Como via de regra, cada codificador deveria fazer uma visitação ampla do website antes de tomar as decisões em relação às diferentes categorias em cada variável. Todavia, como sabemos, a falta de memória digital é um dos principais desafios da comunicação pública no Estado brasileiro (LUZ; WEBER, 2018; SAMPAIO, 2014), então uma série de websites já não estava mais disponível durante a verificação. Nesses casos, foram utilizadas ou o histórico (cash) do google (última menção existente) ou mesmo ferramentas de time machines ${ }^{3}$ da internet, que tendem a ter imagens e informações salvas a respeito de diferentes websites da rede. Para aumentar a confiabilidade tanto das codificações quanto das buscas, cada planilha foi preenchida por dois codificadores independentes. Em caso de conflito, os pesquisadores seniores agiram como juízes para tomar a decisão final ${ }^{4}$. Caso os dados não fossem

\footnotetext{
${ }^{3}$ Cada codificador foi instruído a pesquisar nas seguintes ferramentas: https://archive.org/, http://oldweb.today/, http://archive.org/web/, http://timetravel.mementoweb.org/, http://www.amen.pt/domains/whois.html. Acesso 22 fev. 2018.

${ }^{4}$ Este é um método menos confiável que o teste de confiabilidade padrão entre codificadores, porém, ainda, é mais afiançável que as pesquisas usuais com websites que tendem a ser realizadas unicamente por um único codificador.
} 
confiáveis o suficiente, era optado por não preencher a informação (missing). No anexo 1, está disponível nosso livro de códigos para análise.

\section{Resultados}

Os resultados estão divididos em duas partes. Na primeira, utilizamos estatística descritiva básica para apresentar os resultados gerais e algumas associações. Na segunda parte, iremos utilizar estatística inferencial para testar se é possível encontrar padrões ou variáveis que expliquem o tempo de duração - menor ou maior - de uma iniciativa ou ferramenta. Adotamos como método, neste momento, a análise de sobrevivência. Esse método é particularmente apropriado para a análise que estamos propondo neste artigo, pois ela é destinada a estudos em que a variável dependente (aquela que desejamos explicar) é o tempo até que ocorra algum evento. Como Lins, Figueiredo e Rocha (2017) argumentaram, embora a análise de sobrevivência seja um método amplamente utilizado sobretudo na área médica - em que estudos clínicos verificam o tempo para que um evento ocorra, seja um medicamento fazer efeito ou o paciente morrer - são raras, senão inexistentes, as pesquisas que utilizam este método nas Ciências Sociais. Dessa forma, procuramos estabelecer uma interface metodológica com essas áreas.

Para esta segunda parte, elegemos três variáveis independentes: poder, esfera de governo e temporalidade. Sobre elas, apresentamos as seguintes hipóteses.

\subsection{Descritivos}

Nosso corpus é constituído por 148 casos. Todos compõem os resultados apresentados nesta seção. Em 23 casos, não foi possível descobrir o ano de lançamento ou de encerramento da iniciativa. Portanto, esses casos não entram em nossa análise sobre o tempo de sobrevivência, na segunda seção desses resultados. Dessa forma, a análise seguinte é processada a partir de um número de 125 casos.

Iremos, inicialmente, compreender alguns resultados desta pesquisa sobre ano de lançamento, encerramento e duração. 
Gráfico 1 - Ano de lançamento e encerramento das iniciativas analisadas

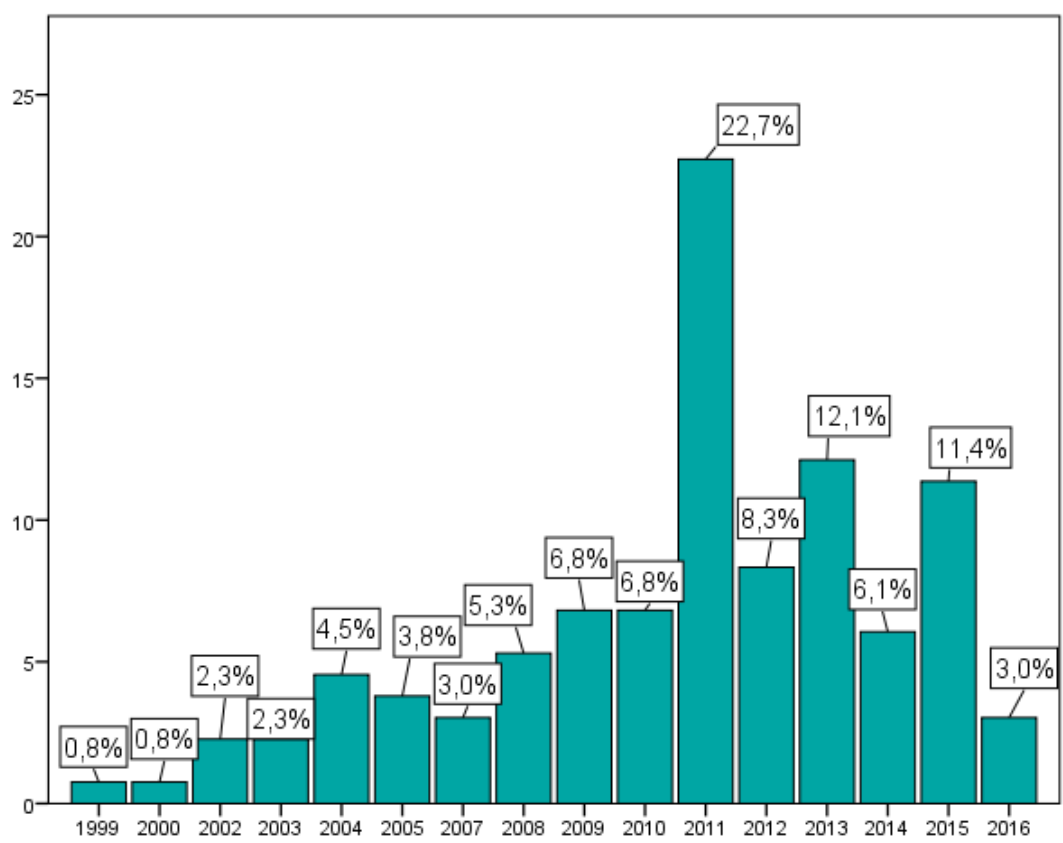

Ano de lançamento

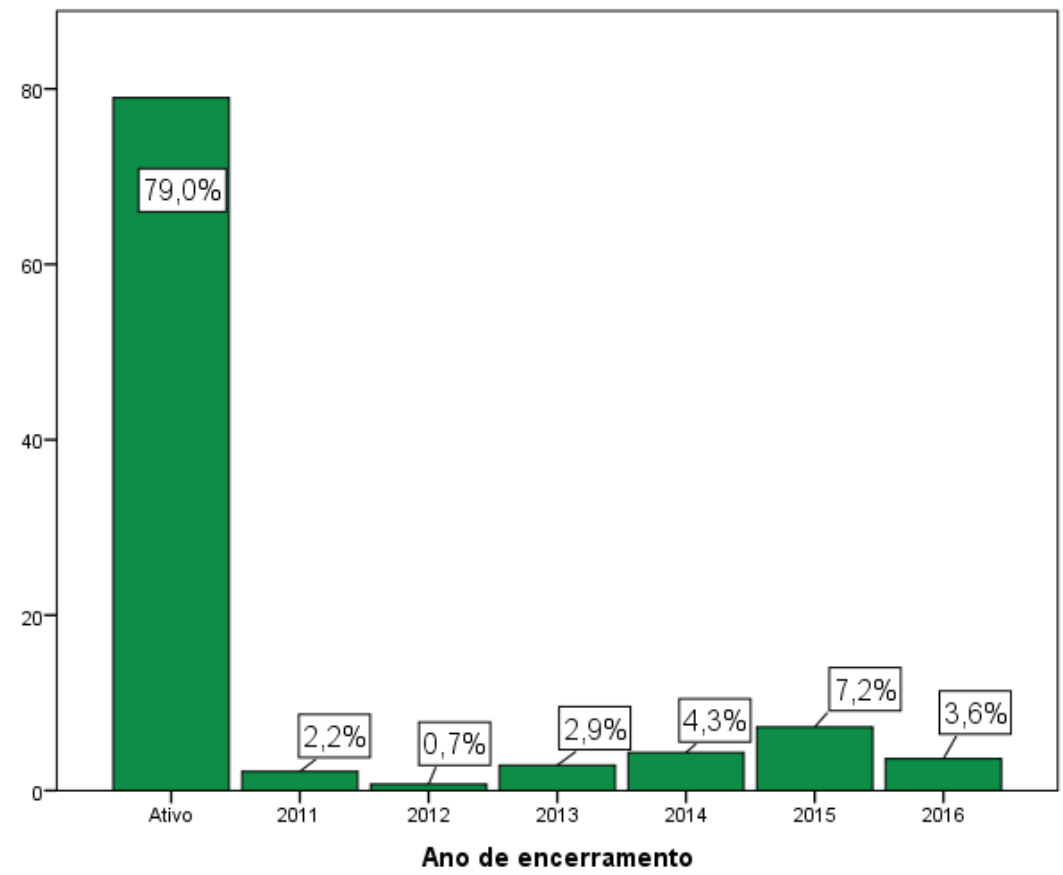

Fonte: elaboração própria. 


\section{Gráfico 2 - Histograma de duração (anos) e status}

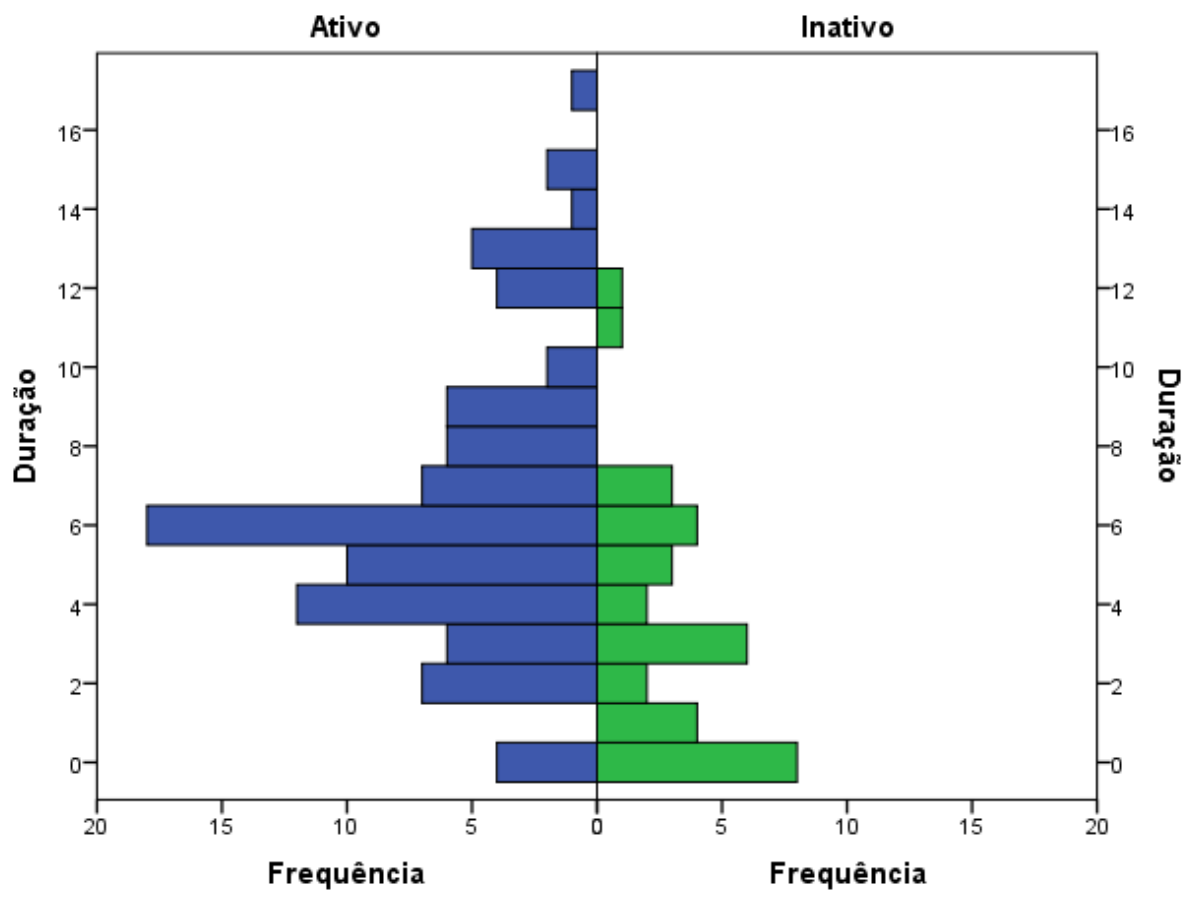

Fonte: elaboração própria.

Do Gráfico 1, percebemos que a maior parte das inciativas ou ferramentas analisadas ainda está ativa (79\%). Contudo, o número de projetos finalizados vinha crescendo anos após ano, tendencialmente, de 2012 até 2015 . A tendência foi interrompida apenas em 2016. Por outro lado, quanto ao ano de lançamento, parece haver maior alternância, com anos ímpares (2013 e 2015) tendo mais projetos iniciados do que em anos pares (2012, 2014 e 2016), o que poderia sugerir certa relação com o período pós-eleitoral. Também chama a atenção, nos anos de lançamento, o "boom" ocorrido no ano de 2011.

Já o histograma do Gráfico 2 indica que há dois picos de "falhas", momentos em que os projetos são abandonados: antes mesmo de completar um ano e com três anos. Além disso, são raras as falhas em iniciativas com mais de sete anos. Dessa forma, já podemos aqui constatar alguns momentos cruciais para a gestão de projetos: o início e a sua "meia-vida". Sobre o tempo de sobrevivência retomaremos adiante. Antes, contudo, é importante conhecermos algumas características do universo analisado.

Em relação ao "tipo", 53,4\% eram do tipo "ferramenta", enquanto 46,8\% eram "iniciativas", o que demonstra equilíbrio entre os dois tipos. A quase totalidade 
adotava dos casos como "plataforma" um website $(89,6 \%)$. A seguir, vieram fórum $(4,9 \%)$, blog $(2,8 \%)$, rede social $(2,1 \%)$ e, por último, wiki $(0,7 \%)$. Nenhuma incidência foi registrada no tipo "aplicativo", o que indica ainda uma falta de adaptação aos padrões de utilização das tecnologias digitais pela população. Na variável "público", 93\% era "amplo", ao passo que apenas 7\% era "restrito" a algum segmento específico, o que demonstra que tais ferramentas são voltadas a um público geral, ainda sem explorar as potencialidades da eventual segmentação.

Os Gráficos 3 e 4 separam, respectivamente, os casos pelas variáveis "poder" e "esfera governamental". O primeiro detém como categorias os Poderes "Executivo", "Legislativo" e "Judiciário" enquanto que a segunda variável possui como categorias as esferas "municipal", "estadual" e "federal". Pelo Gráfico 3 é possível notar que mais da metade dos sites de democracia digital estão hospedados em domínios do Poder Executivo (51,7\%), seguido do Poder Legislativo $(33,8 \%)$ e, por fim, do Judiciário (12,4\%). Quando se trata da esfera governamental (Gráfico 4), temos mais da metade das iniciativas e ferramentas sendo do nível federal (55,5\%). Em segundo lugar, estão em patamares similares os níveis municipal (24\%) e estadual $(20,5 \%)$, indicando a baixa participação dos estados nessas atividades - ao menos em relação ao que poderia ser esperado desses entes.

\section{Gráfico 3 - Esfera de Poder do Estado}

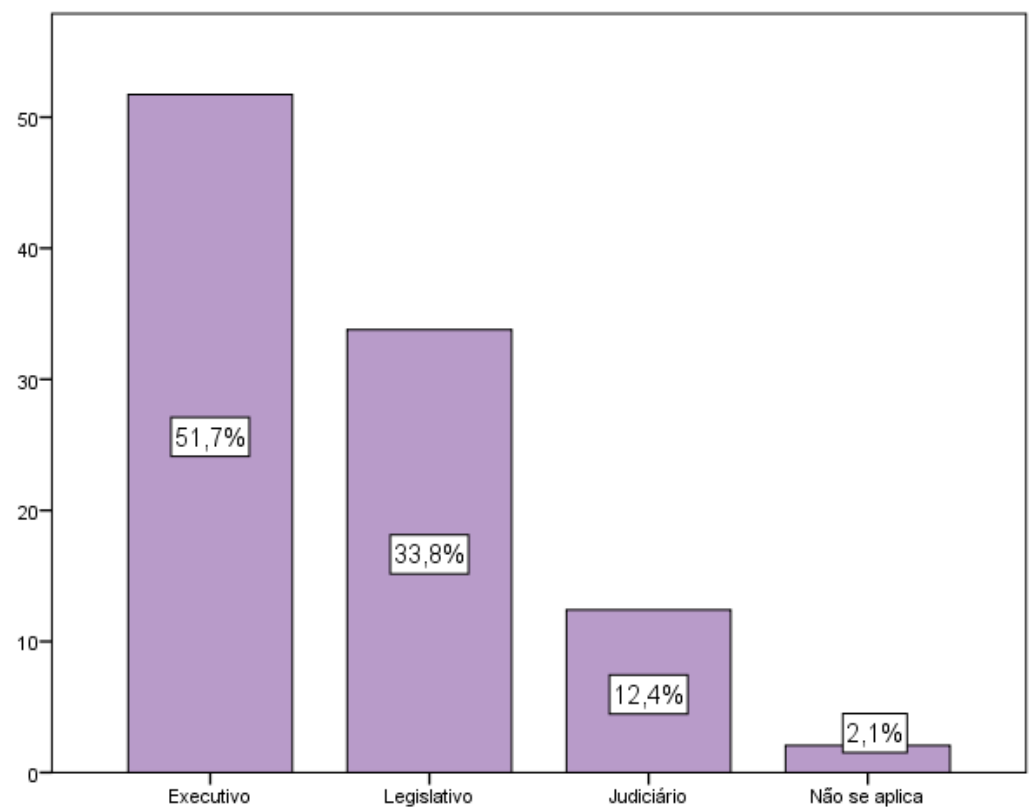

Fonte: elaboração própria. 


\section{Gráfico 4 - Nível da Esfera governamental}

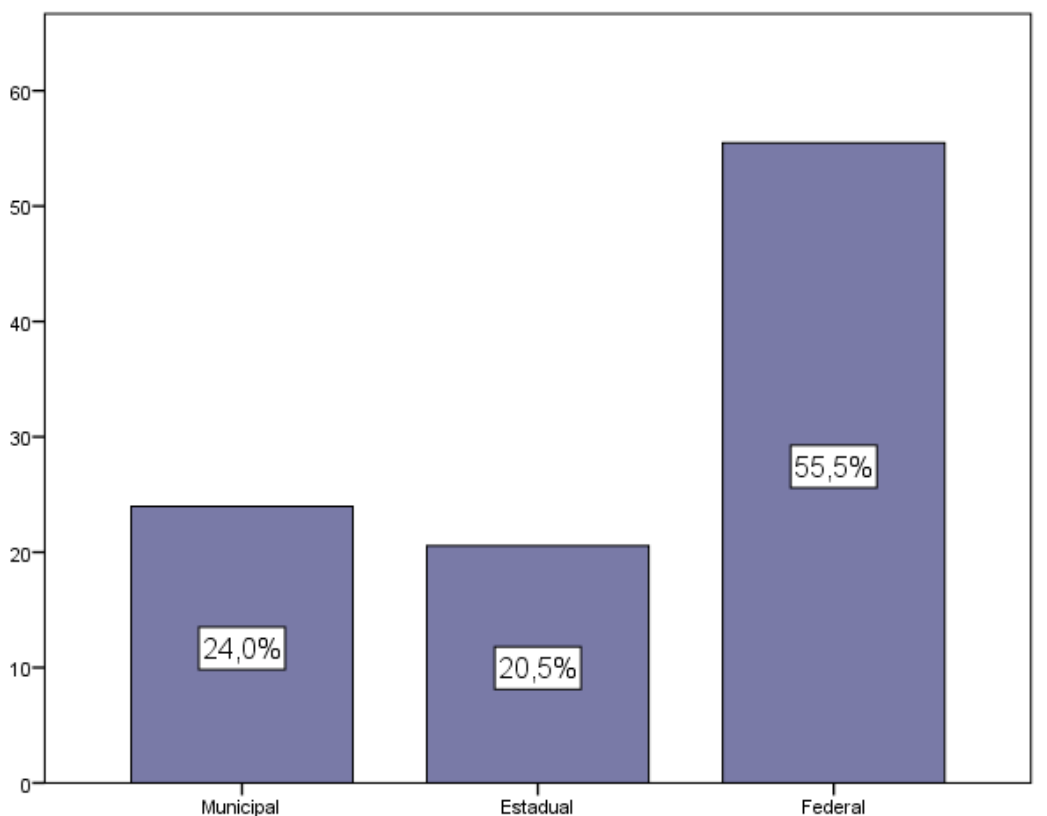

Fonte: elaboração própria.

Tratando da temporalidade dos casos (Gráfico 5), podemos ver que a maioria $(73,4 \%)$ são de temporalidade permanente, contra $20,1 \%$ ocasionais e $6,5 \%$ sazonais. Já referente ao ciclo de políticas públicas, no qual as iniciativas ou ferramentas se encaixam, o Gráfico 6 apresenta alguns dados importantes. A maioria dos casos $(51,6 \%)$ reside na fase de implementação ou monitoramento, ao passo que agenda (23\%) e formulação $(19,7 \%)$ concorrem pelo segundo lugar. Uma parte ínfima se refere às etapas de decisão $(4,1 \%)$ e avaliação $(1,6 \%)$. Isso nos indica que os formuladores desses projetos intentam uma relação com os cidadãos nas etapas iniciais (agenda e formulação) ou na etapa de monitoramento (geralmente referindo-se a projetos de transparência), mas relegam a participação em fases mais críticas ou sensíveis, de decisão ou avaliação. 
Gráfico 5 - Temporalidade das iniciativas de democracia digital

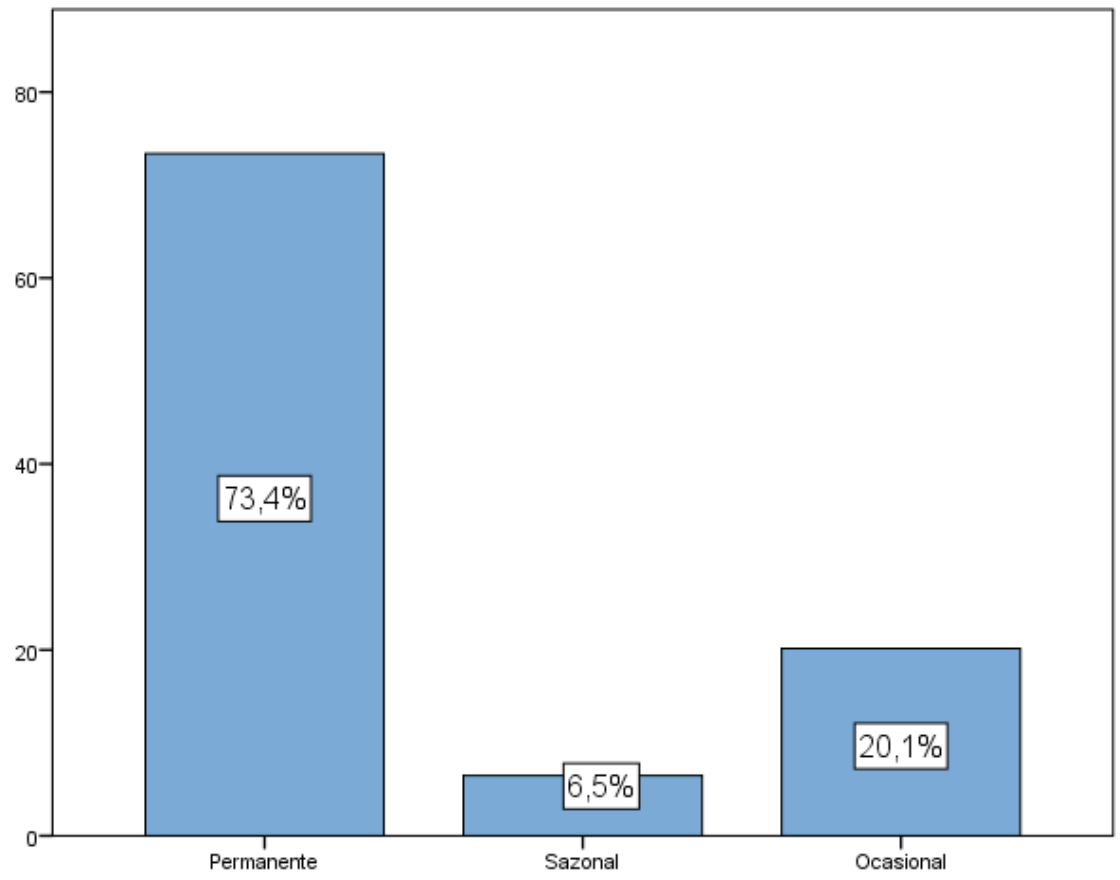

Fonte: elaboração própria.

\section{Gráfico 6 - Clico de políticas públicas das iniciativas de democracia digital}

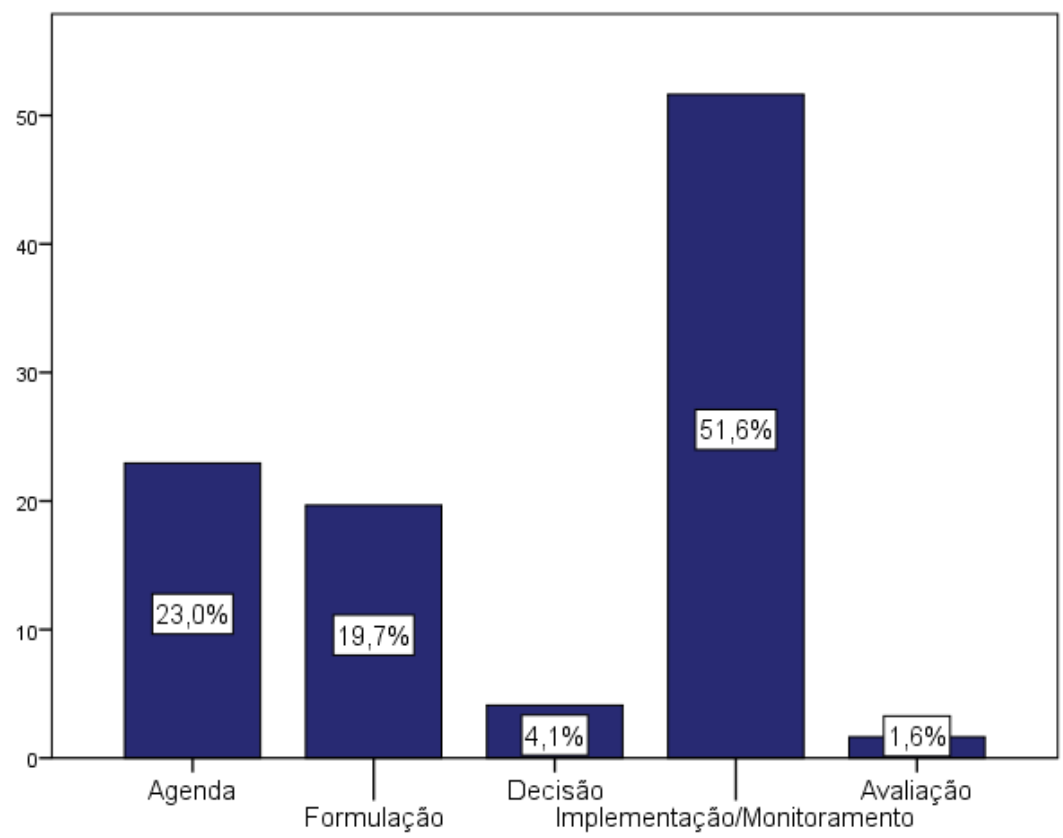

Fonte: elaboração própria. 
Por fim, o conceito de "valor democrático" (Gráfico 7) reflete a ideia subjacente àquela iniciativa ou ferramenta, o conceito sendo contemplado por ela. Aqui, temos uma distribuição bem plural dos casos. Embora "monitoramento de obras, contas e políticas" despontem em primeiro lugar $(29,7 \%)$, vários tipos ocupam patamares próximos, na sequência. Isso indica que existe uma pluralidade democrática que é abarcada por esses projetos.

\section{Gráfico 7 - Valor democrático das iniciativas de democracia digital}

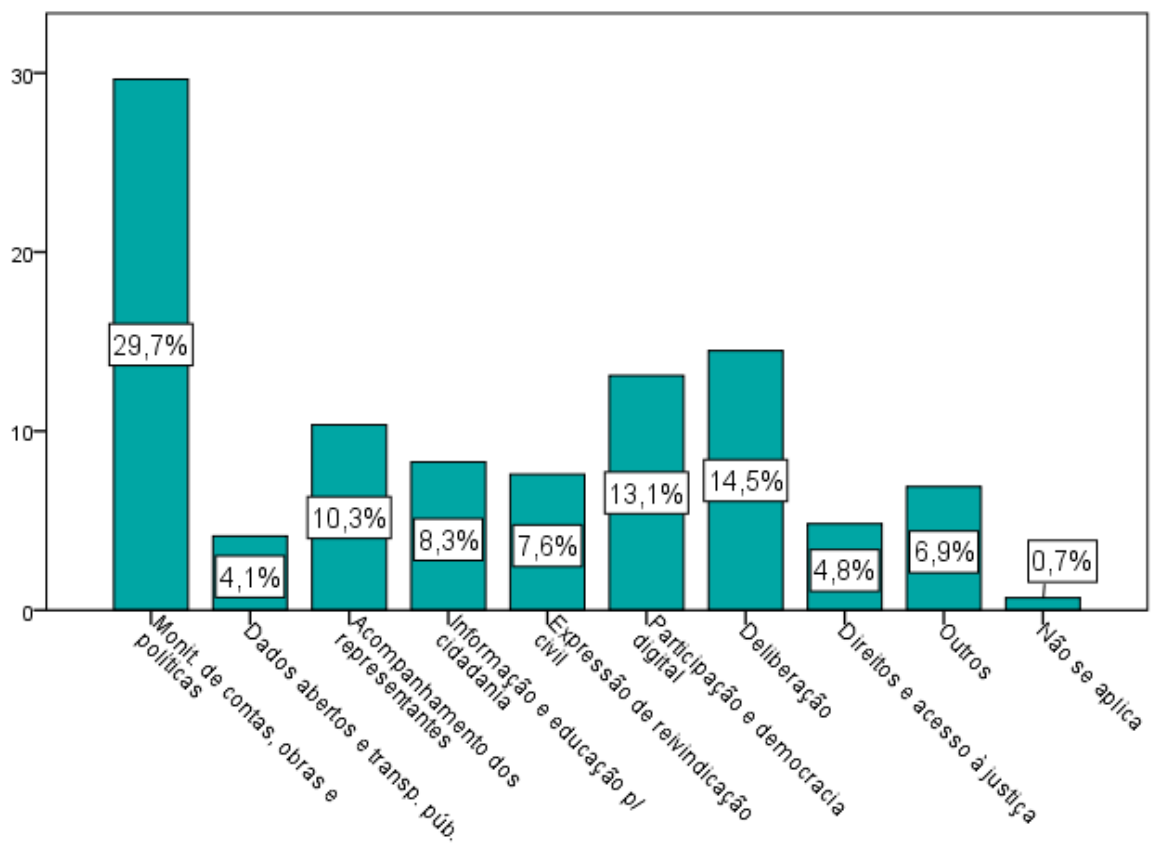

Fonte: elaboração própria.

A seguir, o Gráfico 8 apresenta uma análise de correspondência entre as variáveis esfera de governo, poder e valor democrático. Esse teste verifica a proximidade da ocorrência das variáveis, e nos apresenta os resultados em um campo dimensional. Dessa forma, podemos, com variáveis categóricas, criar e identificar agrupamentos, proximidades e distanciamentos. As linhas indicam as medianas. 


\section{Gráfico 8 - Análise de correspondência}

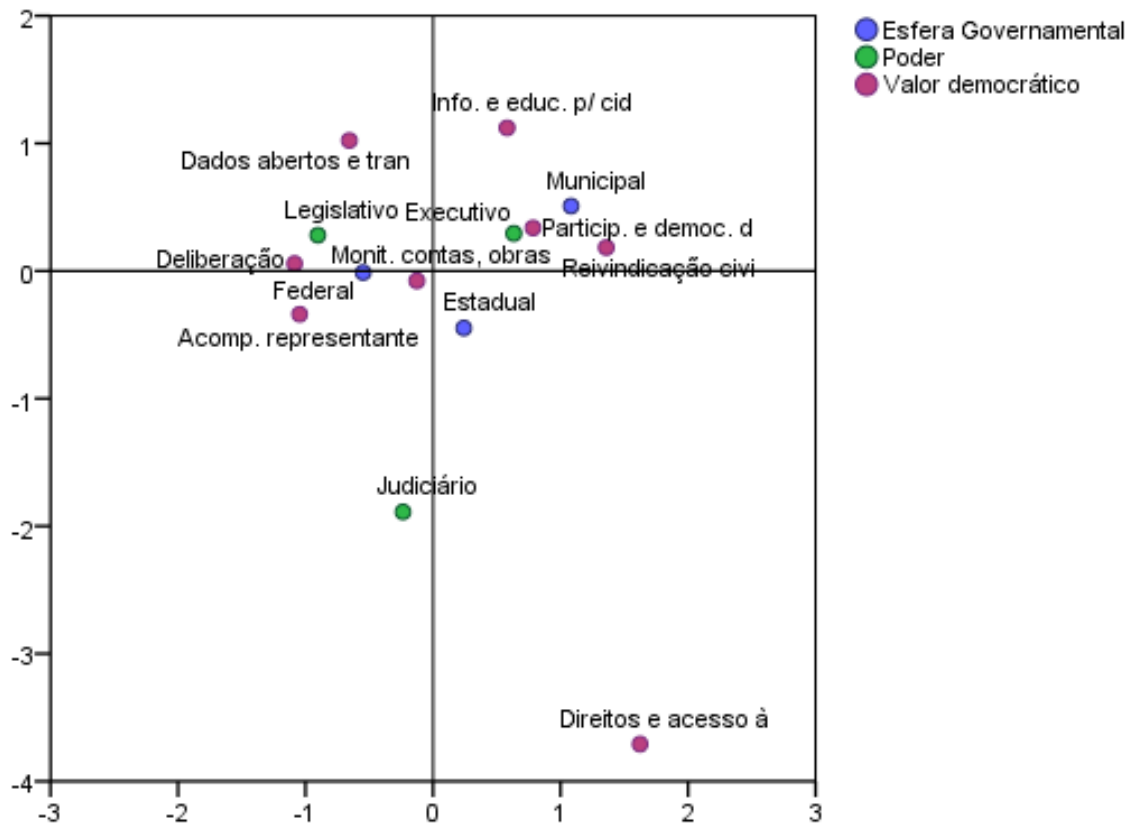

Normalização principal de variável.

Fonte: elaboração própria.

Aqui, podemos claramente identificar alguns clusters. Percebemos no agrupamento direito superior a ocorrência dos valores democráticos "participação e democracia direta", "expressão de reivindicação civil" e "informação e educação para a cidadania", com a esfera municipal e o Poder Executivo. Isso indica que esses elementos tendem a ocorrer de forma conjunta com maior incidência. Também nos mostra que a esfera municipal tem a tendência de lançar iniciativas ou ferramentas voltadas para a participação direta do cidadão.

O segundo fator interessante a ser percebido no Gráfico 8 é a ligação da esfera federal com os valores democráticos "acompanhamento dos representantes", "deliberação", "monitoramento de contas, obras e políticas" e, um pouco mais distante, "dados abertos e transparência pública". A ocorrência em conjunto desses componentes indica que os portais da esfera federal são mais propensos a serem de acompanhamento para o cidadão (colocando em um tema geral).

Um terceiro fator a se retirar desta análise de correspondência se refere ao distanciamento do Poder Judiciário e do valor democrático "direito e acesso à justiça" 
com as demais categorias. Por fim, vale ressaltar que, apesar da esfera estadual aparentar próxima de "monitoramento de contas, obras e políticas", elas não se encontram no mesmo cluster, assim, não podemos indicar uma forte correspondência.

Fizemos uma segunda análise de correspondência, a qual confirmou os resultados explanados da primeira. Podemos dividir o Gráfico 9 em três clusters: (1) direito superior, onde podemos perceber que a esfera federal e o "ciclo de implementação/monitoramento" tendem a ocorrer em conjunto; (2) esquerda inferior, onde a esfera estadual está ligada com o "ciclo de agenda"; e (3) direita inferior, onde vemos a esfera municipal tendendo ao "ciclo de formulação" e "ciclo de avaliação". Também podemos dizer que os portais de democracia digital brasileiros - referentes às esferas municipal, estadual e federal - não tendem a dar o poder de decisão para o cidadão.

\section{Gráfico 9 - Análise de correspondência 2}

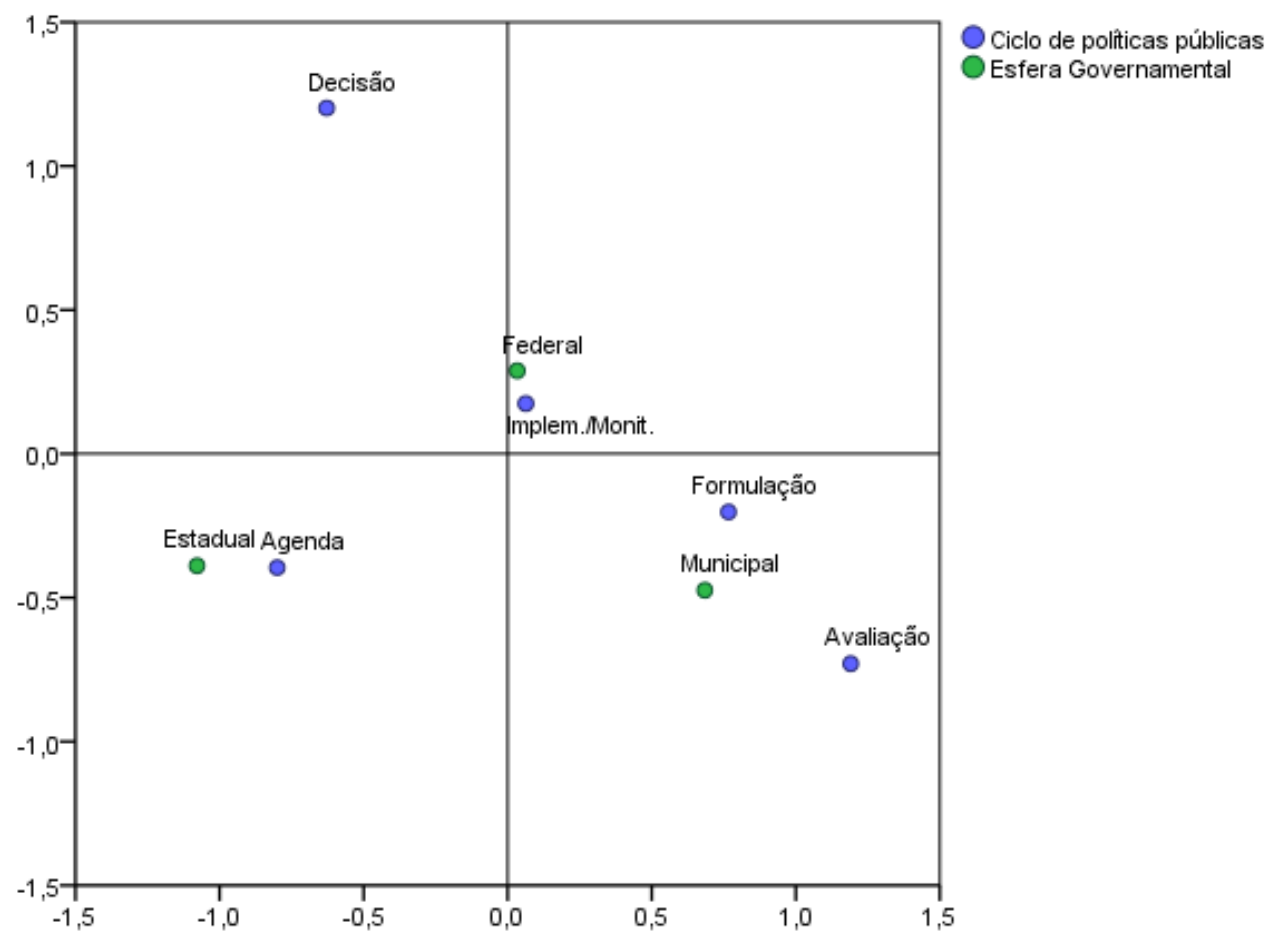

Fonte: elaboração própria. 


\subsection{Análise de sobrevivência}

Nesta seção, iremos proceder com a análise de sobrevivência. Ela é constituída por duas partes. Incialmente, iremos apresentar os padrões de função de sobrevivência, que consistem nos gráficos que demonstram as diferenças no tempo de sobrevivência em cada categoria das variáveis de interesse. A segunda, a chamada regressão de Cox, é um tipo específico de regressão para variáveis dependentes mediadas em tempo. Com a regressão, podemos afirmar ou negar se as diferenças verificadas no tempo de sobrevivência possuem forma explicativa, em termos de causalidade, além de medir o efeito real de cada variável testada.

Os gráficos a seguir apresentam as funções de sobrevivência. No eixo y, podemos verificar a "sobrevivência acumulada" (média em relação ao número de casos em cada tipo) em relação ao período (eixo x). Dessa forma, podemos comparar o ritmo de sobrevivência de cada categoria, nas variáveis testadas.

\section{Gráfico 10 - Sobrevivência - poder}

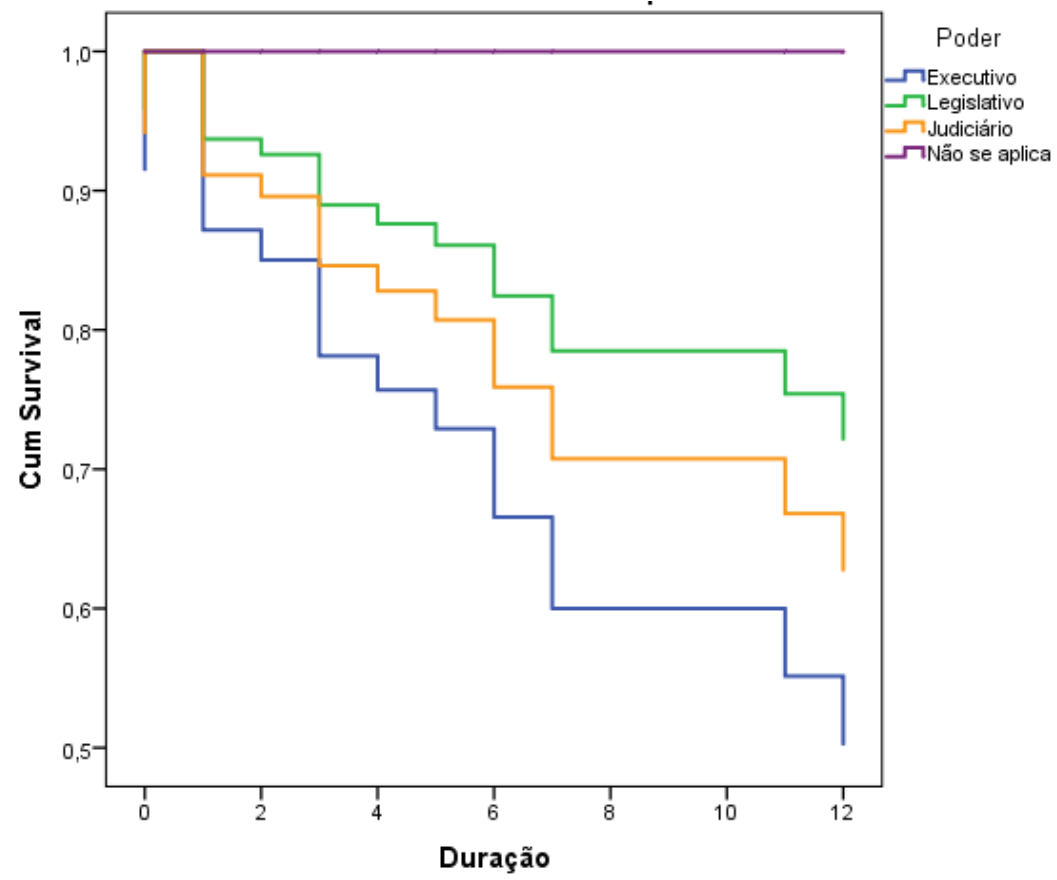

Fonte: elaboração própria. 
Gráfico 11 - Sobrevivência - esfera de governo

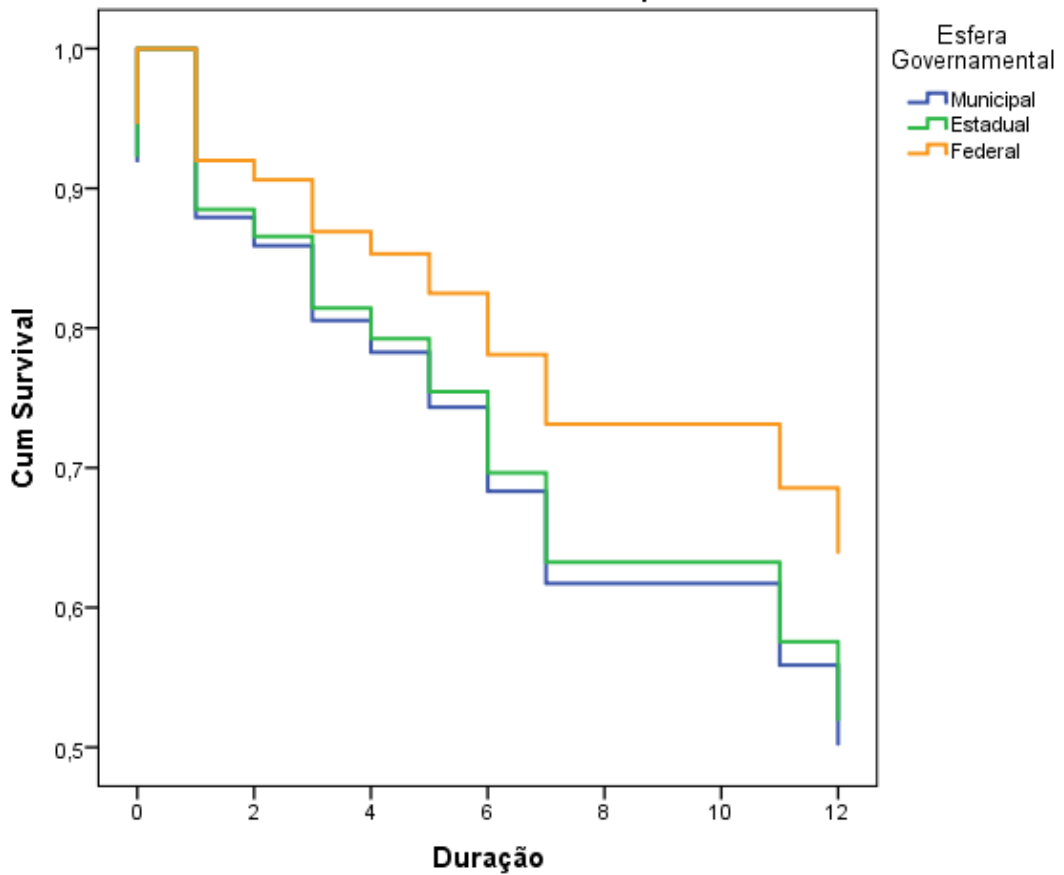

Fonte: elaboração própria.

\section{Gráfico 12 - Sobrevivência - temporalidade}

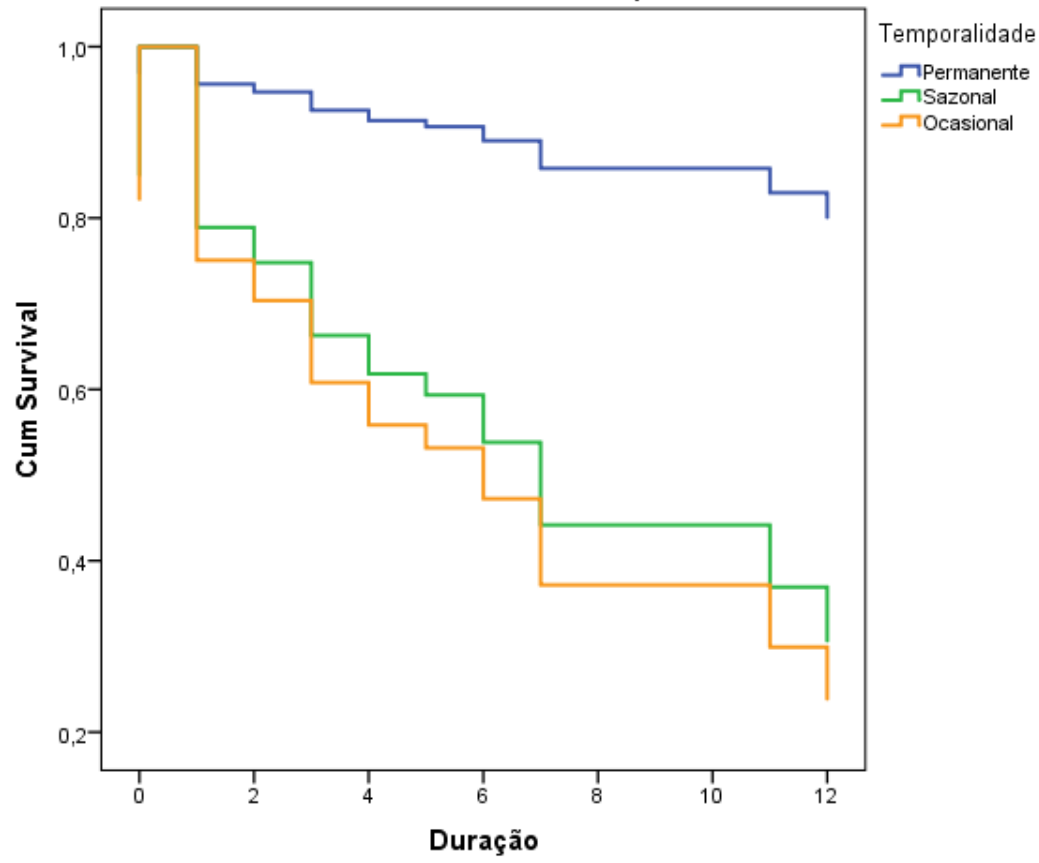

Fonte: elaboração própria. 
Pelos gráficos, podemos verificar que, efetivamente, cada uma das categorias, em cada variável testada, possui tempos de sobrevivência diferentes. Em relação ao poder, verificamos que as ações do Executivo, apesar deste poder ser o que possui maior número de iniciativas - e talvez justamente por isso - são as que possuem maior mortalidade, independente do estágio de vida (se inicial, médio ou avançado). Curiosamente, o Judiciário - que é o poder com menos iniciativas - possui a segunda maior mortalidade, sendo o Legislativo o poder onde as iniciativas menos perecem - no qual há maior taxa de sobrevivência. Movimento em sentido oposto ocorre na variável esfera de governo. O nível federal - que constatamos anteriormente ser aquele com maior parte das iniciativas - é onde a taxa de sobrevivência é maior, com os níveis municipal e estadual, novamente, em patamares equivalentes. No entanto, na variável temporalidade, mostram-se as maiores distâncias entre categorias de uma variável. Enquanto a sobrevivência de iniciativas permanentes permanece acima de $80 \%$, mesmo ao fim dos doze anos que cobrem o recorte, as iniciativas ocasionais e sazonais ficam abaixo dos 30\% de sobrevivência.

Contudo, essas diferenças não significam que tais categorias realmente possuam algum efeito causal, para que as iniciativas/ferramentas falhem mais cedo ou perdurem mais tempo. Por exemplo, as diferenças que verificamos no tempo de sobrevivência entre esferas de governo ou entre poderes podem ser devidas a algum outro fator, que não colocamos na equação. Para realizar essa verificação de causalidade - não mera correlação - iremos proceder com uma regressão para análise de sobrevivência. ${ }^{5}$

Os valores da regressão podem ser lidos como uma regressão tradicional, levando em consideração que os valores indicam a probabilidade de que o evento "falha" ocorra. Uma vez que as variáveis independentes são categóricas, uma das categorias na variável é fixada como base, e os valores das demais são expressos em relação àquela. Qual das variáveis servirá de base não afeta os resultados produzidos. No caso, a variável base não apresenta resultados próprios. Os dois principais indicadores para ler os resultados são o valor-p (sig.), que indica a significância daqueles resultados. Valores sig. abaixo de 0,050 são aceitáveis (indicam que os resultados são confiáveis com uma probabilidade de erro de 0,05\%, e assim em diante, conforme o valor encontrado). Valores acima disso devem ser desconsiderados. A seguir, o valor do bBeta padronizado $(\exp (B))$ indica, tal qual em uma regressão logística, a probabilidade de que o evento ocorra em razão de vezes.

\footnotetext{
${ }^{5}$ Antes de proceder com os resultados finais aqui apresentados, procedemos com uma série de testes exploratórios com diversas variáveis. Entre esses testes preliminares, também testamos "tipo", "valor democrático" e "ciclo de políticas públicas", que não apresentaram nenhum resultado significativo na regressão de Cox.
} 


\section{Tabela 1 -Análise de sobrevivência (regressão de Cox)}

\begin{tabular}{|c|c|c|c|c|c|c|}
\hline & B & SE & Wald & df & Sig. & $\operatorname{Exp}(B)$ \\
\hline $\begin{array}{l}\text { Esfera governamental } \\
\text { (federal) }\end{array}$ & & & ,307 & 2 & ,858 & \\
\hline $\begin{array}{l}\text { Esfera governamental } \\
\text { (municipal) }\end{array}$ & -,174 & ,501 & 120 & 1 & 729 & 840 \\
\hline $\begin{array}{l}\text { Esfera governamental } \\
\text { (estadual) }\end{array}$ & ,182 & ,604 & ,091 & 1 & ,764 & 1,199 \\
\hline Poder (não se aplica) & & & 6,572 & 3 & ,087 & \\
\hline Poder (Executivo) & 8,459 & 114,470 & ,005 & 1 & 941 & 4719,093 \\
\hline Poder (Legislativo) & 6,838 & 114,471 & ,004 & 1 & ,952 & 932,692 \\
\hline Poder (Judiciário) & 8,176 & 114,471 & ,005 & 1 & 943 & 3554,640 \\
\hline $\begin{array}{l}\text { Temporalidade } \\
\text { (permanente) }\end{array}$ & & & 19,472 & 2 & ,000 & \\
\hline $\begin{array}{l}\text { Temporalidade } \\
\text { (sazonal) }\end{array}$ & 1,540 & ,656 & 5,507 & 1 & 019 & 4,667 \\
\hline $\begin{array}{l}\text { Temporalidade } \\
\text { (ocasional) }\end{array}$ & 1,916 & ,442 & 18,760 & 1 & ,000 & 6,793 \\
\hline
\end{tabular}

Fonte: elaboração própria.

Pelos resultados, percebemos que nenhum nível da esfera governamental nem poder apresenta resultados significativos, visto seus altos $p$-values. Contudo, a variável temporalidade apresenta resultados significativos para ambas as variáveis testadas. Iniciativas/ferramentas de cunho sazonal possuem 4 vezes mais chances de falharem do que as permanentes, e as iniciativas/ferramentas ocasionais possuem 6 vezes mais chances de acabarem, também em relação àquelas.

\section{Discussão}

Com a ajuda de um teste de correspondência múltipla, somos capazes de ter uma maior noção das categorias mais próximas entre si, o que indica que o poder Executivo e que a esfera municipal são aqueles que mais promovem os valores "participação e democracia direta", "expressão de reivindicação civil" e "informação e educação para a cidadania". Ademais, no nível federal, temos uma ligação maior com os valores democráticos "acompanhamento dos representantes", "deliberação", "monitoramento de contas, obras e políticas" e, um pouco mais distante, "dados abertos e transparência pública". Finalmente, o Judiciário e o valor democrático 
"direito e acesso à justiça" são aqueles mais distanciados do restante, o que denota um poder menos permeável ao cidadão.

Retomando nossas hipóteses, podemos discutir nossos achados. Cada um dos poderes e dos níveis de governo possuem, efetivamente, tempos de sobrevivência diferentes, como indicado nos Gráficos 9 e 10. Projetos de nível federal e do poder Legislativo são os que tendem a sobreviver por mais tempo, ao passo que projetos não-federais (sejam municipais ou estaduais), assim como do Poder Executivo, tendem a ter menor tempo de vida. Contudo, como indicado na Tabela 1, essas variáveis não possuem poder explicativo causal. Ou seja, essas diferenças existem, mas não são elas o fator explicativo do tempo de sobrevivência menor ou maior das iniciativas/ferramentas. De outro lado, a temporalidade - além de possuir as diferenças observadas no Gráfico 11 - apresenta valores significativos na Tabela 1, indicando ser um fator explicativo para o tempo de sobrevivência de um projeto.

Podemos confirmar parcialmente nossa primeira hipótese, uma vez que o nível federal tende a ter tempo de sobrevivência maior, a despeito da variável não ter sido significativa no modelo de regressão. Sobre a hipótese 2 , ela foi rejeitada inteiramente. Iniciativas/ferramentas do Judiciário não possuem tempo de sobrevivência maior do que suas correspondentes, ficando atrás do Legislativo.

Nossa terceira hipótese se confirmou. Iniciativas ou ferramentas permanentes tendem a ter tempo de sobrevivência maior do que os projetos de tipo ocasional ou sazonal. Acreditamos que a explicação para isso é que os projetos de natureza ocasional ou sazonal, por serem intermitentes, ofertam uma constante possibilidade de reavaliação, diminuindo os custos políticos de finalização do projeto. Tal explicação, contudo, ainda pode vir a ser melhor compreendida no futuro.

\section{Conclusão}

O artigo buscou fazer uma apresentação tanto do estado da arte da democracia digital no Brasil até 2016 quanto compreender questões específicas sobre as conexões entre determinadas iniciativas, poderes e valores democráticos, assim como quais tipos de iniciativas são mais duradouros no caso brasileiro. Não obstante, algumas limitações precisam ser notadas. Em primeiro lugar, todas as pesquisas originais precisam ser consideradas de acordo com seus objetivos originais, ou seja, levantamentos, mapeamentos e prospecções. Em cada uma delas, os pesquisadores podem ter falhado em inventariar determinadas iniciativas, seja por falta de precisão metodológica, falta de treinamento dos codificadores ou simplesmente por erros aleatórios. A agregação de diferentes bancos de dados de levantamentos e prospecções de iniciativas e ferramentas de democracia digital 
parecem ter sido métodos adequados para se ter uma maior e melhor noção do estado da arte no Brasil, mas apenas se reconhecemos esses limites. Em segundo lugar, o relatório mais antigo é de 2010, então é difícil se afirmar o quanto os dados são confiáveis em períodos anteriores a esse. Foram nossos codificadores que buscaram as informações da data de criação e de extinção das plataformas. Em terceiro lugar, pelas descrições apresentadas, os relatórios, como um todo, tentaram mapear todas as iniciativas em nível federal, mas não pareciam dar tanta atenção a níveis menores, o que pode explicar nossos dados, que indicam a maior presença das iniciativas nesse mesmo nível.

Os resultados agregados nos evidenciam o estado da arte das iniciativas de democracia digital no Brasil. Ao contrário do que se pode imaginar, dos 125 casos estudados, $79 \%$ são de ferramentas ou iniciativas que continuam ativas. Elas tendem a ser lançadas em anos ímpares (após as eleições) e os projetos tendem a ser abandonados, prioritariamente, ou no primeiro ano, após o lançamento, ou após três anos. Os casos encontrados ainda demonstram uma pouca utilização de recursos digitais mais avançados, uma vez que mais de $89 \%$ deles são baseados apenas em websites. Respectivamente, Executivo (51,7\%), Legislativo $(33,8 \%)$ e Judiciário $(12,4 \%)$ são aqueles que mais lançam essas iniciativas ou ferramentas. Elas, em sua maioria, são permanentes $(73,4 \%)$, mas há casos de ferramentas/ iniciativas ocasionais $(20,1 \%)$ ou mesmo sazonais (6,5\%). Por sua vez, em termos da fase de políticas públicas, a maioria foi localizada na fase de implementação (51,6\%), mas ainda podemos destacar aquelas na fase de formulação $(19,7 \%)$, sendo poucas aquelas presentes na fase de decisão $(4,1 \%)$ ou avaliação $(1,6 \%)$. Em termos do valor democrático que busca ser avançado, nota-se que a maior parte das iniciativas ou ferramentas se refere ao monitoramento de obras, contas ou políticas $(29,7 \%)$, seguidas por deliberação $(14,5 \%)$, participação $(13,1 \%)$ e acompanhamento dos representantes $(10,3 \%)$.

Esses dados nos ajudam a comprovar questões que já estão presentes na literatura. Via de regra, a maior parte das iniciativas de democracia digital estarão mais próximas ao valor da transparência digital e de acompanhamento de representantes, enquanto chances de participação direta e/ou de deliberação entre os cidadãos serão significativamente menores (ALMADA et al., 2018). Por todas suas capacidades estatais, incluindo as financeiras, o Governo Federal tende a apresentar mais iniciativas, mas o mesmo não se repete na comparação entre capitais e estados, na qual as capitais apresentam mais iniciativas. O Poder Executivo tende a liderar a provisão da democracia digital no Brasil, enquanto o Judiciário ainda é o poder mais opaco a tais possibilidades. Nosso teste de sobrevivência também evidencia algo esperável. Se uma iniciativa é permanente, ela tem mais 
chances de sobreviver (de ser mantida) que uma iniciativa ocasional. Isso reforça o discurso de Coleman e Blumler (2009) contra o excesso de "pilotismo" (iniciativas piloto que nunca se tornam iniciativas plenas) da e-participação. Por outro lado, no caso brasileiro, iniciativas do Legislativo federal tenderam a sobreviver mais que de outros poderes ou níveis, o que é algo bastante reforçado pela persistência do projeto e-democracia. Denota-se, ainda, que a e-democracia brasileira ainda é fortemente baseada em websites, ainda pouco explorando outros recursos, como redes sociais online e aplicativos móveis.

Apesar dos limites de nossa pesquisa, acreditamos que as estratégias metodológicas aplicadas nos permitiram apresentar um compreensivo estado da arte da democracia digital no Brasil, enfatizando os pontos fortes e as lacunas da nossa oferta de iniciativas, ferramentas e projetos na área. Além dos avanços temporais (após 2016), futuras pesquisas podem ser qualitativas com gestores públicos e agentes políticos, para tentar responder a alguns dos achados aqui apresentados.

\section{Referências bibliográficas}

ABREU, J. C. A.; PINHo, J. A. G. Sentidos e significados da participação democrática através da internet: uma análise da experiência do orçamento participativo digital. Revista de Administração Pública, v. 48, n. 4, p. 821-846, 2014.

ALMADA, M. P.; AMORIM, P. K. D. F. E-transparência: proposta de modelo metodológico para avaliação de portais de executivos nacionais. Logos, v. 23, p. 54-67, 2016.

Almada, M. P.; Carreiro, R.; Barros, S. A. R.; Gomes, W. Democracia digital no Brasil: ênfases, estilos e preferências do Poder Executivo federal. In: 27을 Encontro Nacional da Compós - Associação Nacional dos Programas de Pós-Graduação em Comunicação, 2018, Belo Horizonte. Anais do..., 2018.

ARaúso, R. P. A.; Penteado, C. L. C.; SANTOS, M. B. P. Democracia digital e experiências de e-participação: webativismo e políticas públicas. História, Ciências, SaúdeManguinhos, v. 22, p. 1597-1619, 2015.

BARros, S. A. R. Os desafios das consultas públicas online: lições do Marco Civil da Internet. Link em Revista, v. 12, n. 1, 2016.

BARros, S. A. R. Consultas online e democracia digital: um estudo comparativo da participação no Brasil e nos Estados Unidos. Tese (Doutorado em Comunicação) Faculdade de Comunicação, Universidade Federal da Bahia, Salvador, p. 233, 2017.

BARROS, S. A. R.; SAMPAIO, R. C. A confiança para a manutenção de uma inovação democrática: o caso do orçamento participativo digital de Belo Horizonte. Cadernos Gestão Pública e Cidadania, v. 22, n. 72, 2017.

Bragatto, R. C.; SAMPaio, R. C.; Nicolás, M. A. A segunda fase da consulta do Marco Civil da Internet: como foi construída, quem participou e quais os impactos. Revista 
Eptic, v. 17, n. 1, p. 237-255, 2015.

Capone, L. V.; Ituassu, A.; Pecoraro, C. Twitter e esfera pública: pluralidade e representação na discussão sobre o Marco Civil da Internet. Revista Contracampo, v. 33, n. 2, p. 86, 2015.

Centro de Estudos Avançados em Democracia Digital (Ceadd). Relatório de prospecção sobre democracia digital no Brasil: análise exploratória de sítios governamentais e iniciativas civis. Relatório de Pesquisa, 2010.

Centro De Estudos Avançados Em Democracia Digital (CEAdD). Democracia digital no Brasil: sítios governamentais. Relatório de Pesquisa, 2011.

Centro de Estudos avançados Em Democracia Digital (CEAdD). Democracia digital no Brasil: uma prospecção das melhores iniciativas federais de 2015. Relatório de Pesquisa, 2015.

Coelho, T. R.; Silva, T. A. B.; CunhA, M. A.; TeixeirA, M. A. C. Transparência governamental nos estados e grandes municípios brasileiros: uma dança dos sete véus incompleta? Cadernos de Gestão Pública, v. 23, p. 235-260, 2018.

COMITÊ GeSTOR DA INTERNET No BRASIL (CGI.br). Pesquisa sobre o uso das tecnologias de informação e comunicação - TIC Governo Eletrônico 2015. São Paulo: CGI.br, 2016.

CHADWICK, A. Explaining the failure of an online citizen engagement initiative: the role of internal institutional variables. Journal of Information Technology \& Politics, v. 8, p. 21-40, 2011.

COLEMAN, S.; BRUMLER, J. The internet and democratic citizenship: theory, practice and policy. Cambridge: Cambridge University Press, 2009.

DAHLBERG, L. Re-constructing digital democracy: an outline of four 'positions'. New Media \& Society, v. 13, n. 6, p. 855-872, 2011.

FARIA, C.; Rehbein, M.; SATHLeR, A. Netizen em ação: hackeando o parlamento a partir de dentro. In: Silva, S.P.; BRAgatTo, R.C.; SAMPaIO, R.C. (Org.). Democracia digital, comunicação política e redes. Folio Digital: Rio de Janeiro, 2016, p. 393-418. FERREIRA, D. E. S. Uma análise comparada do impacto dos usos das novas tecnologias digitais na dinâmica participativa e deliberativa dos orçamentos participativos de Belo Horizonte e Recife. Tese (Doutorado em Ciência Política), Universidade Federal de Minas Gerais, Belo Horizonte, 2012.

Fundação Getúlio Vargas (FGV). Projeto Democracia Digital. v. 1: Panorama da transparência governamental no Brasil. Relatório de Pesquisa, 2015a.

FundaÇÃo GetúlIo VARGAS (FGV). Projeto Democracia Digital. v. 2: Experiências governamentais brasileiras de participação digital. Relatório de Pesquisa, 2015b.

FREITAS, C. S.; FIUZA, F.; QUEIROZ, F. Os desafios ao desenvolvimento de um ambiente para participação política digital: o caso de uma comunidade virtual legislativa do projeto e-democracia no Brasil. Organizações \& Sociedade, v. 22, p. 639-657, 2015. GOMES, W. Participação política online: questões e hipóteses de trabalho. In: MAIA, R. C. M.; Gomes, W.; MARques, F. P. J. A. (org.). Internet e Participação política no Brasil. Porto Alegre: Sulina, 2011, p. 19-45. 
GOMES, W. 20 anos de política, Estado e democracia digitais: uma cartografia do campo. In: Silva, S.P.; Bragatto, R.C.; SAMPaio, R.C. (Org.). Democracia digital, comunicação política e redes: teoria e prática. Rio de Janeiro, Editora Letra \& Imagem, 2016, p. 25-45.

GRÖNLUND, Â. Emerging electronic infrastructures: exploring democratic components. Social Science Computer Review, v.. 21, n. 1, p. 55-72, 2003.

LINS, R.; FIgUEIREDO FILHO, D.; RoCHA, E. Não temos tempo a perder: uma introdução à análise de sobrevivência. Revista Política Hoje, v. 26, n. 1, p. 279-298, 2017.

LUZ, A. J.; WEBER, M. H. Comunicação governamental e memória política. In: BENETTI, Márcia; BALDISSERA, Rudimar. (Org.). Pesquisa e Perspectivas de Comunicação e Informação. Porto Alegre: Sulina, 2018, v. 1, p. 15-37.

MACINTOSH, A.; WHYTE, A. Towards an evaluation framework for e-participation. Transforming government: people, process and policy, v. 2, n. 1, p. 16-30, 2008.

MAGALHÃES, L. Instâncias e mecanismos de participação em ambientes virtuais: análise das experiências de participação política online em políticas públicas. In: 39a Encontro Anual da Anpocs - Associação Nacional de Pós-Graduação e Pesquisa em Ciências Sociais, 2015, Caxambu. Anais do 39o Encontro Anual da Anpocs, de 26 a 30 de outubro de 2015, Caxambu - MG., 2015.

MAIA, R. C. M.; ReZENDE, T. A. S. Respect and disrespect in deliberation across the networked media environment: examining multiple paths of political talk. Journal of Computer-Mediated Communication, v. 21, p. 121-139, 2016.

MARques, F. P. J. A. "Muro baixo, o povo pula": iniciativas institucionais de participação digital e seus desafios fundamentais. Opinião Pública, v. 16, p. 117142, 2010a.

MARques, Â. C. S.; MARTINO, L. M. S. Deliberação online e opinião pública no caso do movimento Gota d' Água contra a usina de Belo Monte. Contemporanea, Salvador, v. 10, p. 530-556, 2012.

MEndonca, R. F.; SAMPaIO, R. C.; BARRos, S. A. R. (Org.). Deliberação online no Brasil: entre iniciativas de democracia digital e redes sociais de conversação. Salvador: Edufba, 2016.

Mendonça, R. F.; Pereira, M. A.; FIlgueiras, F. (Org.). Democracia digital: publicidade, instituições e confronto político. Belo Horizonte: Editora UFMG, 2016.

Mitozo, I. B.; Marques, F. P. J. A.; Mont'Alverne; C. Como se configura a comunicação online entre representantes e representados no Brasil? Um estudo sobre as ferramentas digitais da Câmara dos Deputados. Contracampo, v. 35, n. 2, 2016.

NEUENDORF, K. The content analysis guidebook. Londres: Sage, 2003.

NicolÁs, M. A.; BRAGA, S. As elites parlamentares sul-americanas e as NTICS: perfil sociopolítico e o uso da web por deputados e senadores do Brasil, Argentina, Chile, Paraguai, Uruguai e Venezuela. Revista NEP - Núcleo de estudos paranaenses da UFPR, v. 1, p. 61, 2015. 
NoRRIS, P. A digital divide: civic engagement, information: poverty and the internet in democratic societies. New York: Cambridge University Press, 2001.

PINHo, J. A. G. Investigando portais do governo eletrônico de estados no Brasil: muita tecnologia, pouca democracia. Revista de Administração Pública, v. 42, n.3, p.471-93, 2008.

Possamal, A. J. Dados abertos no Governo Federal brasileiro: desafios de transparência e interoperabilidade. $311 \mathrm{f}$. Tese - Programa de Pós-Graduação em Ciência Política, Universidade Federal do Rio Grande do Sul, Porto Alegre, 2016.

RAUPP, F. M.; PERFOLL, A. P. Construindo a transparência em assembleias legislativas dos estados brasileiros: uma investigação nos portais eletrônicos. Revista de Administração e Contabilidade da FAT, v. 5, n. 2, p. 04-20, 2017.

RIBEIRO, M. M.; BARBosA, A. F. Medição do uso da internet para a participação: desafios para governo e sociedade no Brasil. In: Silva, S.P.; BRAGATTO, R.C.; SAMPAIO, R.C. (Org.). (Org.). Democracia digital, comunicação política e redes: teoria e prática. 1ed. Rio de Janeiro: Folio Digital: Letra e Imagem, 2016, p. 161-188.

SAMPAIO, R. C. Orçamentos participativos digitais: um mapeamento mundial das experiências já realizadas e suas contribuições para e-participação e e-democracia. 364f. Tese (Doutorado em Comunicação) - Faculdade de Comunicação, Universidade Federal da Bahia, Salvador, 2014.

SARmento, R.; MendonçA, R. F. Luana, Eliza e a Lei Maria da Penha: o acontecimento em discussão. Contemporanea, v. 15, n. 3, p. 842-865, 2018.

Silva, S. P.; Rabelo, L. E. M.; Santos, É.; Luciano, M. S. Parlamento digital, transparência e dados abertos: análise qualitativa dos datasets da Câmara dos Deputados. Trabalho apresentado no 1 o Congresso do INCT.DD, set. 2018, Salvador - Bahia.

VAN DIJK, J. Digital democracy: vision and reality. Public Administration in the Information Age, v. 19, p. 49, 2012.

VEDEL, T. The idea of electronic democracy: origins, visions and questions. Parliamentary Affairs, v. 59, n. 2, p. 226-235, 2006. 


\section{Rafael Cardoso Sampaio}

Universidade Federal do Paraná (UFPR). Doutor em Comunicação e Cultura Contemporânea pela Universidade Federal da Bahia, UFBA. Professor do Departamento de Ciência Política da Universidade Federal do Paraná. Pesquisador do Instituto Nacional de Ciência e Tecnologia em Democracia Digital (INCT.DD). cardososampaio@ gmail.com, http://lattes.cnpq.br/6603480808884218, http://orcid.org/0000-0001-5176-173X

\section{Sérgio Braga}

Universidade Federal do Paraná (UFPR). Doutor em Desenvolvimento Econômico, IE-Unicamp. Professor do Departamento de Ciência Política da Universidade Federal do Paraná.Pesquisador do Instituto Nacional de Ciência e Tecnologia em Democracia Digital (INCT.DD). sssbraga@gmail.com http://lattes.cnpq.br/7410355460141681 http://orcid.org/0000-0003-3397-0575

\section{Marcio Cunha Carlomagno}

Universidade Federal do Paraná (UFPR). Doutorando do Programa de Pós-Graduação em Ciência Política da Universidade Federal do Paraná. Pesquisador do Instituto Nacional de Ciência e Tecnologia em Democracia Digital (INCT.DD). mccarlomagno@gmail.com, http://lattes.cnpq.br/1524587715569821, https://orcid. org/0000-0002-1145-1523

\section{Djiovanni Jonas França Marioto}

Universidade Federal do Paraná (UFPR). Mestrando em Ciência Política pela Universidade Federal do Paraná, UFPR. Bacharel em Ciências Sociais pela Universidade Federal do Paraná, UFPR. Pesquisador do Instituto Nacional de Ciência e Tecnologia em Democracia Digital (INCT.DD). djiovannimarioto@gmail.com, http://lattes.cnpq. br/7304355871572210, https://orcid.org/0000-0002-6485-5927

\section{Murilo Brum Alison}

Universidade Federal do Paraná (UFPR). Graduando em Ciências Sociais pela Universidade Federal do Paraná (UFPR). murilo43@hotmail.com, http://lattes.cnpq.br/0068799420504338, https://orcid.org/0000-0001-9224-1407.

\section{Tiago Philippini Ferreira Borges da Silva}

Universidade Federal do Paraná (UFPR). Bacharel em Ciências Sociais pela Universidade Federal do Paraná (UFPR). tpfbsilva@gmail.com, http://lattes.cnpq.br/5394676136400406, https://orcid.org/0000-0001-9647-8225

Todos os autores são pesquisadores associados do Instituto Nacional de Ciência e Tecnologia em Democracia Digital - INCT.DD 


\section{Anexo 1}

\section{Livro de códigos da pesquisa sobre democracia digital no Brasil}

\section{1) Nome da iniciativa ou ferramenta (string)}

Preencher o nome da iniciativa ou ferramenta por extenso. Caso seja uma iniciativa que contém várias ferramentas, preencher apenas o nome geral da iniciativa e responder todas as perguntas abaixo tendo a iniciativa como forma de avaliação.

\section{2) URL (string)}

Endereço da internet na qual se localiza a ferramenta ou plataforma. Verificar.

\section{3) Ano de lançamento (string)}

Verificar o ano de lançamento da iniciativa ou plataforma e preencher numericamente (e.g. "2015"). Esta informação deve ser inicialmente buscada na própria plataforma oficial (e.g. ferramenta de busca). Tentar procurar por palavras como "lançamento" e relacionadas. Em último caso, recorrer ao google e considerar a primeira referência temporal como aquela a ser preenchida.

\section{4) Ano de encerramento (string)}

Frequentemente, se o site não está no ar, não haverá referências sobre o fim do programa. Neste caso, procurar por termos como "cancelado" ou "descontinuado" (e relacionadas) no google junto com o nome da iniciativa (entre aspas). Em último caso, considerar o ano da última notícia referente ao site/ferramenta como sendo o final. Caso ainda não seja possível verificar de maneira confiável, preencher como "99" (missing).

Caso a iniciativa ainda esteja ativa, preencher como "88". 


\section{5) Tipo (categórica)}

Diferenciação entre iniciativas de democracia digital e ferramentas de democracia digital. Conforme discutido, a iniciativa geralmente se refere a um projeto, programa ou instituto mais elaborado ou ainda à uma conjunção de ferramentas (um domínio por exemplo). Porém, dentro de websites ou redes sociais, é possível que haja ferramentas, instrumentos de democracia digital. Por exemplo, um orçamento participativo digital ou o e-democracia são iniciativas. Por sua vez, a opção "fale com seu deputado" é apenas uma ferramenta dentro do website da Câmara dos Deputados. Caso seja uma iniciativa com várias ferramentas, marcar apenas "iniciativa". Preencher apenas o número.

1. iniciativa

2. ferramenta

\section{6) Plataforma(categórica)}

Diferentemente da variável acima, o objetivo aqui é verificar qual é a principal plataforma utilizada pela iniciativa ou ferramenta. Apenas uma variável pode ser preenchida. A listagem abaixo representa uma hierarquia. Ou seja, o website só deve ser preenchido se não há nenhuma outra opção relevante. Por exemplo, evidentemente, todo fórum de discussão está dentro de website ou blog, mas para nós é mais relevante verificar o número de fóruns presentes.

1. app

2. fórum

3. wiki

4. rede social

5. blog

6. website

1.

\section{7) Esfera governamental(categórica)}

Qual a esfera governamental responsável pela iniciativa

1. Municipal

2. Estadual

3. Federal 


\section{8) Poder(categórica)}

Qual o poder brasileiro responsável pela iniciativa

1. Executivo

3. Judiciário

\section{9) Temporalidade (categórica)}

Qual a frequência de realização de atividades

1. Permanente (i.e. sempre aberto para participação, escrutínio etc.)

2. Sazonal (ex. bienal, como é o caso de orçamentos participativos)

3. Ocasional (ex. consulta, como é o caso da consulta do Marco Civil)

\section{0) Atividade(dummy)}

O programa está ativo ou não.

0 . Inativo

1. Ativo

\section{1) Estado(string)}

Preencher nominalmente o nome do estado no qual se localiza a ferramenta ou iniciativa. Preencher como "FEDERAL" em caso de iniciativa federal.

\section{2) Cidade(string)}

Preencher nominalmente o nome da cidade na qual se localiza a ferramenta ou iniciativa. Preencher como "FEDERAL" em caso de iniciativa federal.

\section{3) A qual fase do ciclo de políticas públicas está vinculado?} (categórica)

1. Agenda (primeira fase do ciclo; problema retratado em detalhes e possíveis soluções descritas conforme as partes interessadas.)

2. Formulação (onde todas as partes interessadas definem a solução para um problema específico de forma que o planejamento seja fundido em um plano concreto.)

3. Decisão (tomada de decisão a respeito da possível execução da política formulada.) 
4. Implementação/monitoramento (é a execução do plano concreto definido na fase da formulação, cabendo às partes interessadas engajar-se na realização, monitoramento e divulgação do projeto.)

5. Avaliação (fase final em que todas as partes interessadas e envolvidas podem efetuar o feedback e, caso seja necessário, reiniciar o ciclo.)

\section{4) Valor democrático (categórica)}

1. Monitoramento de contas, obras e políticas (refere-se à capacidade dos indivíduos e grupos fora da organização para monitorar as atividades e decisões tomadas dentro da organização.)

2. Dados abertos (disponibilidade de informações sobre uma organização ou ator.)

3. Acompanhamento dos representantes (permite o acompanhamento, por parte da sociedade, de representantes através da disponibilização de informações e ferramentas que facilitam a comunicação, além de mecanismos de prestação de contas.)

4. Informação e educação para a cidadania (utilização das TICs como recurso de ativação da cidadania, aumentando o acesso e a disponibilidade da participação, afim de promover governos e sociedades justas e eficientes.)

5. Expressão de reivindicação civil (ferramentas voltadas para fazer reclamações, denúncias ou pedidos ao órgão público, como 156, Colab)

6. Participação (participação direta da sociedade civil no processo de tomada de decisão, geralmente envolvendo o voto.)

7. Deliberação (formas de participação que envolvam algum tipo de ferramenta dialógica)

8. Direitos e acesso à justiça (ferramentas ou iniciativas que sejam voltadas para minorias e/ou para fortalecimento de direitos individuais e direitos humanos)

9. Outros. 


\section{Anexo 2}

\section{Nome da iniciativa ou ferramenta}

\#GABINETEABERTO

@

Acessa SP

Acompanhe a tramitação

Acompanhe seu

deputado

Alô senado online

Aplicativos.Gov (Portal

Brasil)

Atividade legislativa (senado)

Atlas Social da Matriz de Informação Social (MDS)

Audiência Pública Interativa (Senado)

Audiências Públicas Encerradas de 2015 da ANAC

Banco de Dados - Talento Esportivo nas escolas

Base Nacional Comum Curricular

Blog do deputado BRASIL.GOV

BRASIL.GOV - governo eletrônico - consultas públicas

Café Hacker SP

Canteiro de Obras
URL

http://saopauloaberta.prefeitura.sp.gov.br/index.php/ conheca-o-gabineteaberto/

$\underline{\text { http://pararesponde.pa.gov.br/?page id=2 }}$

http://www.acessasp.sp.gov.br/

http://www2.camara.leg.br/atividade-legislativa/projetos-delei-e-outras-proposicoes/acompanhamento-de-proposicoespor-e-mail

http://www2.camara.leg.br/transparencia/sispush/ indexAtuacao

http://www.senado.gov.br/senado/alosenado/default.asp

http://www.aplicativos.gov.br/

http://www25.senado.leg.br/web/atividade/

http://aplicacoes.mds.gov.br/sagi/mi2007/mapas/tela programas mds nicolle.php

http://www12.senado.leg.br/ecidadania/principalaudiencia

http://www.anac.gov.br/participacao-social/audiencias-econsultas-publicas/audiencias-encerradas/2015

http://www.brasil.gov.br/esporte/2009/10/descoberta-dotalento-esportivo-nas-escolas

http://historiadabncc.mec.gov.br/\#/site/relatorios-analiticos

http://www.al.rs.gov.br/site/ http://www.portaltransparencia.gov.br/

http://www.governoeletronico.gov.br/eixos-de-atuacao/ cidadao/arquivo-consultas-publicas

http://cafehacker.prefeitura.sp.gov.br/

http://obras.curitiba.pr.gov.br/ 
Combate à corrupção (MPF)

Condiç̧̃̃es das Rodovias

Conheça os deputados

Consulta Pública

(Senado)

Consulta Pública Lei

Rouanet

Consulta pública online

Consulta Pública para

construção do Edital

Pontos de Mídia Livre

Consulta Pública SUS

Consultas Públicas (Min.

Saúde)

Consultas Públicas

ANATEL

\section{Consultas Públicas \\ ANCINE \\ Consultas Públicas encerradas ANS \\ Consultas públicas \\ INMETRO}

Consultas Públicas CNPq

Cota para exercício da atividade parlamentar

(Câmara Federal)

Custos de Mandato

Dados Abertos (Câmara

Federal)

Dados Abertos (Senado)

DADOS.GOV.BR (Portal

Brasil) http://www.combateacorrupcao.mpf.mp.br/

http://servicos.dnit.gov.br/condicoes/

http://www2.camara.gov.br/deputados/pesquisa

http://www12.senado.leg.br/ecidadania/

visualizacaoconsultapublica?id=322

$\underline{\text { http://culturadigital.br/inleirouanet/ }}$

http://www.almg.gov.br/participe/consulta_publica/index. $\underline{\mathrm{html}}$

http://culturadigital.br/cidadaniaediversidade/2015/05/13/ aberta-a-consulta-publica-para-construcao-do-edital-pontosde-midia-livre/

http://200.214.130.94/CONSULTAPUBLICA/INDEX. PHP?MODULO=DISPLAY\&SUB=DSP CONSULTA

http://www.saude.gov.br/consultapublica

http://sistemas.anatel.gov.br/SACP/Contribuicoes/

http://sad.ancine.gov.br/consultapublica/consultaPublica.

http://cnpq.br/consultas-publicas/

http://www.ans.gov.br/participacao-da-sociedade/consultase-participacoes-publicas/consultas-publicas-encerradas

http://www.inmetro.gov.br/qualidade/iaac/consulta-publica. asp

http://www.camara.gov.br/cota-parlamentar/

http://www.camara.sp.gov.br/transparencia/custos-demandato/

http://www2.camara.leg.br/transparencia/dados-abertos

http://dadosabertos.senado.gov.br/

http://dados.gov.br/ 
Tiago Philippini Ferreira Borges da Silva

DATASENADO (Senado) $\quad$ http://www12.senado.leg.br/institucional/datasenado

Delegacia Digital (Antiga

Delegacia Interativa)

https://www.delegaciadigital.ssp.ba.gov.br/

Denúncia Eletrônica

https://www.sefin.ro.gov.br/denuncia.jsp

Denuncie O Nepotismo

http://www.controladoria.al.gov.br/denuncia

Departamento Legislativo

(Portal da Transparência

da Câmara Municipal de

http://portaldatransparencia.cmfor.ce.gov.br/

Fortaleza)

Desafio ágora rio

https://desafioagorario.crowdicity.com/

Despesas (Portal da

Transparência do governo http://www.portaltransparencia.gov.br/Despesas.asp

federal)

Dicionário do Parlamento

http://www.camarademacapa.com.br/pagina.php?pg=exibir conteudo\&idmenuP $=30$

DPU - Pesquisa de

Qualidade dos Serviços

Prestado

http://www.dpu.gov.br/index.php?option=com content\&view=article\&id=4329\&/temid=320

e-Democracia (Câmara

Federal)

http://edemocracia.camara.gov.br/

Educação à Distância

http://www.almg.gov.br/educacao/educacao distancia/

Entenda como funciona o http://portalpbh.pbh.gov.br/pbh/contents.

Processo Legislativo

do?evento $=$ conteudo $\&$ idConteudo $=60530 \& \mathrm{chPlc}=60530$

Envie sua sugestão de projeto de lei

http://www.almg.gov.br/participe/envie_sugestao_lei/index. $\underline{\mathrm{html}}$

Frequência de reuniões no plenário

http://www.cmm.am.gov.br/frequencia2006.asp

Gabinete civil do Alagoas

http://www.gabinetecivil.al.gov.br/

Gabinete de Segurança Institucional - Consultas públicas

http://www4.planalto.gov.br/legislacao/consultaspublicas\#content

Gabinete Digital http://www.gabinetedigital.rs.gov.br

Gamificando o http://www.participa.br/gamificacao/gamificando-o\#participabr participabr

Gestão Urbana SP http://gestaourbana.prefeitura.sp.gov.br/ 


\begin{tabular}{|c|c|}
\hline Governo eletrônico & $\begin{array}{l}\text { http://www.mg.gov.br/governomg/portal/c/ } \\
\text { governomg/governo/acoes-do-governo/5813- } \\
\text { projetosestruturadores/62719-governo- } \\
\text { eletronico/5794/5040 }\end{array}$ \\
\hline Habitat III Participa Brasil & $\begin{array}{l}\text { http://www.participa.br/habitat/habitat-iii-participa-brasil\#. } \\
\text { VVK9YyFVikq }\end{array}$ \\
\hline Histórico de votações & http://www.aleac.net/agregador/deputados \\
\hline $\begin{array}{l}\text { Ideias Legislativas } \\
\text { (Senado) }\end{array}$ & http://www12.senado.leg.br/ecidadania/principalideia \\
\hline $\begin{array}{l}\text { II Fórum de } \\
\text { Desenvolvimento } \\
\text { Sustentável de Roraima }\end{array}$ & $\begin{array}{l}\text { http://www.seplan.rr.gov.br/index.php?option=com } \\
\text { content\&task=view\&id=173\&ltemid=101 }\end{array}$ \\
\hline Kit cidadania & $\begin{array}{l}\text { http://www.almg.gov.br/opencms/opencms/educacao/ } \\
\text { publicacoes multimidia/publicacoes-multimidia-kit.html }\end{array}$ \\
\hline $\begin{array}{l}\text { Laboratório de Inovação } \\
\text { Colaborativa Digital da } \\
\text { IplanRio }\end{array}$ & http://www.lincdigital.com.br/ \\
\hline LDO 2016 & http://www.participa.br/monitoramento/pldo2016 \\
\hline $\begin{array}{l}\text { Legislação (Câmara } \\
\text { Federal) }\end{array}$ & $\underline{\text { http://www2.camara.leg.br/atividade-legislativa/legislacao }}$ \\
\hline $\begin{array}{l}\text { Mapa da Justiça (Min. } \\
\text { Justiça) }\end{array}$ & $\begin{array}{l}\text { http://www.acessoajustica.gov.br/pub/sobre/ } \\
\text { portasDaJustica/consultarPortasDaJustica. } \\
\text { faces;jsessionid=Q9zQ1blu6iZNWXV4avSFvtUB.undefined }\end{array}$ \\
\hline $\begin{array}{l}\text { Mapa Digital Oficial de } \\
\text { Porto Alegre }\end{array}$ & http://geoobservatorio.palegre.com.br/geoobservatorio/ \\
\hline $\begin{array}{l}\text { Mapa Vivo de Obras - } \\
\text { Santa Catarina }\end{array}$ & $\begin{array}{l}\text { http://www.sicop.sc.gov.br/mapavivo/mapa. } \\
\text { isp?ObrasEmergenciais=\&cdOrgaosetor }=\end{array}$ \\
\hline Mapeando & $\underline{\text { http://mapeando.rio.gov.br }}$ \\
\hline Marco Civil da Internet & http://pensando.mj.gov.br/marcocivil/ \\
\hline Medidas Anticorrupção & http://pensando.mj.gov.br/anticorrupcao/ \\
\hline $\begin{array}{l}\text { Melhorias nos modelos } \\
\text { de licenças aceitas pelo } \\
\text { SPB }\end{array}$ & $\begin{array}{l}\text { http://www.participa.br/softwarepublico/melhorias-nos- } \\
\underline{\text { modelos-de-licencas-aceitas-no-spb }}\end{array}$ \\
\hline $\begin{array}{l}\text { Ministério da Cultura - } \\
\text { Consultas públicas }\end{array}$ & http://pnc.culturadigital.br/ \\
\hline $\begin{array}{l}\text { Ministério da Educação } \\
\text { - Painel de controle do } \\
\text { MEC }\end{array}$ & http://painel.mec.gov.br/ \\
\hline
\end{tabular}


Tiago Philippini Ferreira Borges da Silva

\begin{tabular}{|c|c|}
\hline Ministério da Justiça & http://www.justica.gov.br/Acesso/licitacoes-e-contratos \\
\hline Ministério da Saúde & http://aplicacao.saude.gov.br/portaltransparencia/index.jsf \\
\hline $\begin{array}{l}\text { Ministério da Saúde - } \\
\text { Consulta pública }\end{array}$ & $\begin{array}{l}\text { http://200.214.130.94/CONSULTAPUBLICA/INDEX. } \\
\text { PHP?MODULO=DISPLAY\&SUB=DSP CONSULTA }\end{array}$ \\
\hline $\begin{array}{l}\text { Ministério das } \\
\text { Comunicações - } \\
\text { Licitações - Contratos }\end{array}$ & $\begin{array}{l}\text { http://www.comunicacoes.gov.br/licitacoes-e-contratos/ } \\
\text { editais-e-avisos }\end{array}$ \\
\hline $\begin{array}{l}\text { MPF - Portal } \\
\text { Transparência }\end{array}$ & http://www.transparencia.mpf.gov.br/ \\
\hline $\begin{array}{l}\text { MPU - Documentos e } \\
\text { Publicações }\end{array}$ & $\begin{array}{l}\text { http://www.mpu.gov.br/navegacao/documentos-e- } \\
\text { publicacoes }\end{array}$ \\
\hline Orçamento Participativo & $\begin{array}{l}\text { http://www2.portoalegre.rs.gov.br/op/default.php?p } \\
\underline{\text { secao }=82 \#}\end{array}$ \\
\hline $\begin{array}{l}\text { Orçamento Participativo } \\
\text { de Recife }\end{array}$ & http://www.recife.pe.gov.br/op/index.php \\
\hline $\begin{array}{l}\text { Orçamento Participativo } \\
\text { Digital } 2011\end{array}$ & http://opdigital2011.pbh.gov.br/index.php \\
\hline $\begin{array}{l}\text { Orçamento Participativo } \\
\text { Digital } 2013\end{array}$ & https://opdigital.pbh.gov.br \\
\hline Orçamento Temático & http://www12.senado.leg.br/orcamento/tematico \\
\hline $\begin{array}{l}\text { Página para denúncia de } \\
\text { crimes contra os direitos } \\
\text { humanos na internet da } \\
\text { Polícia Federal ?(Min. } \\
\text { Justiça) }\end{array}$ & http://denuncia.pf.gov.br/ \\
\hline Participa.br & $\underline{\text { http://www.participa.br }}$ \\
\hline Participatório & http://juventude.gov.br/participatorio\#.VUilrvlVikp \\
\hline Passaporte de serviços & $\begin{array}{l}\text { http://www.cms.ba.gov.br/tv_camara int. } \\
\underline{\text { aspx?id=259\&tipo=programa }}\end{array}$ \\
\hline $\begin{array}{l}\text { Planalto.gov - Galeria de } \\
\text { áudios }\end{array}$ & http://www2.planalto.gov.br/multimidia/galeria-de-audios \\
\hline $\begin{array}{l}\text { Planalto.gov - Galeria de } \\
\text { vídeos }\end{array}$ & http://www2.planalto.gov.br/multimidia/galeria-de-videos \\
\hline PlanejaSampa & $\underline{\mathrm{http}: / / \text { planejasampa.prefeitura.sp.gov.br/ }}$ \\
\hline $\begin{array}{l}\text { Plano Nacional de Cultura } \\
\text { (PNC) }\end{array}$ & http://pnc.culturadigital.br/revisaodasmetas/destaque/ \\
\hline Plataforma Itec (MCTI) & http://www.plataformaitec.com.br/ \\
\hline
\end{tabular}




\begin{tabular}{|c|c|}
\hline Plenarinho & $\underline{\text { http://www.plenarinho.gov.br/ }}$ \\
\hline Portal 1746 & http://www.1746.rio.gov.br/ \\
\hline Portal Brasil - Cidadania* & http://www.brasil.gov.br/sobre/cidadania \\
\hline Portal da Cidadania** & http://comunidades.mda.gov.br \\
\hline $\begin{array}{l}\text { Portal da Gurizada - Porto } \\
\text { Alegre }\end{array}$ & http://www.camarapoa.rs.gov.br/portaldagurizada/ \\
\hline $\begin{array}{l}\text { Portal da legislação } \\
\text { (Portal Brasil) }\end{array}$ & http://www4.planalto.gov.br/legislacao \\
\hline $\begin{array}{l}\text { Portal da Saúde (Min. da } \\
\text { saúde) }\end{array}$ & http://portalsaude.saude.gov.br/index.php/servicos \\
\hline Portal da Transparência & http://www.portaltransparencia.gov.br/ \\
\hline $\begin{array}{l}\text { Portal da Transparência } \\
\text { - Judiciário }\end{array}$ & http://www.portaltransparencia.jus.br/despesas/ \\
\hline $\begin{array}{l}\text { Portal da Transparência - } \\
\text { Amapá }\end{array}$ & $\underline{\text { http://transparencia.ap.gov.br/ }}$ \\
\hline $\begin{array}{l}\text { Portal da Transparência - } \\
\text { Copa } 2014\end{array}$ & http://www.transparencia.gov.br/copa2014/ \\
\hline $\begin{array}{l}\text { Portal da Transparência - } \\
\text { Paraná }\end{array}$ & http://www.alep.pr.gov.br/transparencia/ \\
\hline $\begin{array}{l}\text { Portal da Transparência - } \\
\text { Senado }\end{array}$ & http://www.senado.gov.br/transparencia/ \\
\hline $\begin{array}{l}\text { Portal da Transparência } \\
\text { de Curitiba (Antes } \\
\text { "Curitiba Aberta") }\end{array}$ & http://www.curitibaaberta.curitiba.pr.gov.br/ \\
\hline $\begin{array}{l}\text { Portal de Serviços do } \\
\text { Governo Federal }\end{array}$ & http://www.servicos.gov.br/ \\
\hline Portal Dialoga Brasil & $\underline{\text { http://dialoga.gov.br/ }}$ \\
\hline $\begin{array}{l}\text { Portal dos } \\
\text { Colegiados**** }\end{array}$ & $\begin{array}{l}\text { http://portalpbh.pbh.gov.br/pbh/ecp/comunidade. } \\
\underline{\text { do?app=conselhos }}\end{array}$ \\
\hline $\begin{array}{l}\text { Portal e-Cidadania - } \\
\text { Senado }\end{array}$ & $\underline{\text { http://www12.senado.leg.br/ecidadania }}$ \\
\hline $\begin{array}{l}\text { PPA Participativo Espírito } \\
\text { Santo }\end{array}$ & http://www.ppaonline.es.gov.br/ \\
\hline PPA Participativo RS & http://www.participa.rs.gov.br \\
\hline Processo On-line & http://projetos.camarapoa.rs.gov.br/projetos \\
\hline
\end{tabular}


Tiago Philippini Ferreira Borges da Silva

\section{Programa Dados Abertos}

Projetos de lei e outras proposições

Proteção de dados pessoais

Quadro de pessoal e estrutura remuneratória da Câmara dos Deputados

Rede Mineira de Gestão das Águas

Reformulação da Lei Orgânica do Município de Salvador

\section{Rio Estado Digital}

SAC - (Serviço de atendimento ao cidadão) SP

\section{Salários Abertos}

SIOPS (Min. Saúde)

Sistema de Apoio ao

Processo Legislativo (SAPL)

Sistema de busca e cruzamento de informações sobre o processo legislativo

Sistema de Informações para Infância e Adolescência - SIPIA (Secretaria de Direitos Humanos)

Sistema de Informações sobre Foco de Trabalho Infantil (Min. do Trabalho http://sistemasiti.mte.gov.br http://www.camara.sp.gov.br/index.php?option=com content\&view=category\&layout=blog\&id $=115 \& \mid$ temid $=205$

http://www.camara.gov.br/sileg/default.asp

http://pensando.mj.gov.br/dadospessoais/

http://www2.camara.gov.br/transparencia/recursoshumanos/quadro-remuneratorio

http://redemineira.igam.mg.gov.br/

http://www.cms.ba.gov.br/lom.aspx

$\underline{h t t p: / / w w w . r i o e s t a d o d i g i t a l . r i . g o v . b r ~}$

http://sac.prefeitura.sp.gov.br/

http://www.camara.sp.gov.br/transparencia/salariosabertos/

http://portalsaude.saude.gov.br/index.php/o-ministerio/ principal/siops

http://200.164.108.163:9673/sapl/default index html

http://www.sapl.ac.gov.br:8087/sapl_site/sapl_skin/sapl skin index html

http://www.sipia.gov.br/CT/?x=3Ju1D5wXDwD5qFSVH*uxNg e Emprego) 


\author{
Sistema de \\ monitoramento \\ (Secretaria de Políticas de http://monitoramento.seppir.gov.br/ \\ Promoção da Igualdade \\ Racial)

\begin{tabular}{|c|c|}
\hline Sistema Fala Salvador & http://www.falasalvador.ba.gov.br/ \\
\hline SP 2040 & $\begin{array}{l}\text { O link que possuímos (http://www.sp2040.net.br/) não leva } \\
\text { mais ao projeto SP } 2040-\mathrm{A} \text { cidade que queremos }\end{array}$ \\
\hline $\begin{array}{l}\text { STF - Acompanhamento } \\
\text { processual }\end{array}$ & http://www.stf.jus.br/portal/processo/pesquisarProcesso.asp \\
\hline STF - Estatísticas & $\begin{array}{l}\text { http://www.stf.jus.br/portal/cms/verTexto. } \\
\text { asp?servico=estatistica\&pagina=movimentoProcessual }\end{array}$ \\
\hline $\begin{array}{l}\text { STF - Linha Sucessória de } \\
\text { Ministros }\end{array}$ & http://www.stf.jus.br/portal/cms/verTexto. \\
\hline STF - Transparência & $\begin{array}{l}\text { http://www.stf.jus.br/portal/contaPublicaCompra/ } \\
\text { pesquisarCompra.asp }\end{array}$ \\
\hline $\begin{array}{l}\text { TJ-AM: Produtividade } \\
\text { Juízes }\end{array}$ & $\begin{array}{l}\text { http://www.tjam.jus.br/index.php?option=com } \\
\underline{\text { content\&view=article\&id=6763\&/temid }=867}\end{array}$ \\
\hline TJ-ES: Justiça Colaborativa & http://www.justicacolaborativa.com.br/site/ \\
\hline TJ-MA: JurisConsult & http://jurisconsult.tjma.jus.br/ \\
\hline $\begin{array}{l}\text { TJ-RN - Portal da } \\
\text { Transparência }\end{array}$ & http://www.tirn.jus.br/portalTransparencia/despesas.aspx \\
\hline TJ-RS: Doar é Legal & https://doarelegal.tjrs.jus.br/ \\
\hline $\begin{array}{l}\text { Transparência - Rio } \\
\text { Grande do Norte }\end{array}$ & http://www.transparencia.rn.gov.br/ \\
\hline Transparência na Copa & http://www.transparencianacopa.com.br/obras \\
\hline TSE - Eleições Anteriores & $\begin{array}{l}\text { http://www.tse.jus.br/eleicoes/eleicoes-anteriores/eleicoes- } \\
\text { anteriores }\end{array}$ \\
\hline $\begin{array}{l}\text { TSE - Estatísticas do } \\
\text { Eleitorado }\end{array}$ & $\begin{array}{l}\text { http://www.tse.jus.br/eleitor/estatisticas-de-eleitorado/ } \\
\text { estatisticas-de-eleitorado }\end{array}$ \\
\hline TV Câmara - Cuiabá & http://www.camaracba.mt.gov.br/index.php?pag=tv \\
\hline Web CHAT PBH & http://j.mp/uQOJgm \\
\hline $\begin{array}{l}\text { Wikilegis (Câmara } \\
\text { Federal) }\end{array}$ & http://beta.edemocracia.camara.leg.br/wikilegis/ \\
\hline
\end{tabular} \\ Fonte: elaboração própria. \\ Os links foram retirados dos relatórios originais e atualizados quando possível. Alguns não estão mais disponíveis.
}

